\title{
Investigating the utility of ecoacoustic metrics in marine soundscapes
}

\section{Original paper}

Article history:

Received: 15 May 2018

Accepted: 3 August 2018

Published: 14 September 2018

Check for updates

*Correspondence:

DRB: drbohnen@incsu.edu

Peer review:

Double blind

\section{Copyright:}

(c) 2018 Bohnenstiehl et al. @ This is an open access article distributed under the Creative Commons Attribution License (CC-BY 4.0), which permits unrestricted use, distribution, and reproduction in any medium, provided the original work is properly cited and its authors credited.

\section{Keywords:}

acoustic indices; acoustic ecology; marine soundscapes; call rate; acoustic complexity index; acoustic entropy

\section{Citation:}

Bohnenstiehl D. R., Lyon R. P., Caretti O. N., Ricci S. W., Eggleston D. B. (2018). Investigating the utility of ecoacoustic metrics in marine soundscapes. Journal of Ecoacoustics. 2: \#R1156L. https://doi.org/10.22261/JEA.R1156L

\author{
DelWayne R. Bohnenstiehl ${ }^{1,2,{ }^{*}}$, R. Patrick Lyon ${ }^{1,3}$, Olivia N. Caretti ${ }^{1,3}$, \\ Shannon W. Ricci, ${ }^{1,2}$, David B. Eggleston ${ }^{1,3}$ \\ ${ }^{1}$ Department of Marine Earth and Atmospheric Sciences, North Carolina State University, 2800 \\ Faucette Dr., Raleigh, North Carolina 27695, USA \\ ${ }^{2}$ Center for Geospatial Analytics, North Carolina State University, 2800 Faucette Dr., Raleigh, \\ North Carolina 27695, USA \\ ${ }^{3}$ Center for Marine Science and Technology, North Carolina State University, 303 College Circle, \\ Morehead City, North Carolina 28557, USA
}

\begin{abstract}
Soundscape analysis is a potentially powerful tool in ecosystem monitoring. Ecoacoustic metrics, including the Acoustic Complexity Index (ACl) and Acoustic Entropy $(\mathrm{H})$, were originally developed for terrestrial ecosystems and are now increasingly being applied to investigate the biodiversity, habitat complexity and health of marine systems, with mixed results. To elucidate the efficacy of applying these metrics to marine soundscapes, their sensitivity to variations in call rate and call type were evaluated using a combination of field data and synthetic recordings. In soundscapes dominated by impulsive broadband snapping shrimp sounds, $\mathrm{ACl}$ increased nonlinearly with increased snapping rate ( 100-3500 snaps/min), with a percent range of variation $(\sim 40-50 \%)$ that exceeds that reported in most studies. $H$, however, decreased only slightly ( 0.04 units) in response to these same snap rate changes. The response of these metrics to changes in the rate of broadband snapping was not strongly influenced by the spectral resolution of the analysis. For soundscapes dominated by harmonic fish calls, increased rates of calling ( $5-120$ calls/min) led to decreased $\mathrm{ACl}$ ( $\sim 20-40 \%$ range of variation) when coarse spectral resolutions $(\Delta f=94$ or $47 \mathrm{~Hz}$ ) were used in the analysis, but $\mathrm{ACl}$ increased ( $20 \%$ range of variation) when a finer resolution $(\Delta \mathrm{f}=23 \mathrm{~Hz})$ was employed. Regardless of spectral resolution used in the analysis, $H$ decreased $(\sim 0.20$ units $)$ in response to increased rates of harmonic calling. These results show that $\mathrm{ACl}$ and $\mathrm{H}$ can be modulated strongly by variations in the activity of a single sound-producing species, with additional sensitivity to call type and the resolution of the analysis. Variations in $\mathrm{ACl}$ and $\mathrm{H}$, therefore, cannot be assumed to track call diversity, and the utility of these metrics as ecological indicators in marine environments may be limited.
\end{abstract}

\section{Introduction}

The assessment of biodiversity is critical in addressing questions of ecosystem health and resilience. Traditional methods of ecological survey, however, are often time consuming, invasive and limited by accessibility to the environment. As many species emit sounds while moving, foraging and interacting with one another, passive acoustic monitoring provides an alternative method to constrain the diversity and behavior of animals (Rountree et al., 2006; Farina, 2014; Farina and Gage, 2017). This approach is relatively low-cost, minimally-disruptive, and can be deployed semi-continuously over long time periods. Acoustic recording 
may be particularly useful within underwater habitats where visibility and access are generally more limited than in terrestrial systems (Willis, 2001; Freeman et al., 2014; Tricas and Boyle, 2014).

In the terrestrial realm, a suite of soundscape metrics has been developed to gain information about the acoustic environment (Sueur et al., 2008a, 2014; Pieretti et al., 2011; Depraetere et al., 2012). These parameters represent the complexity or evenness of the acoustic environment using a single value to characterize a recorded audio segment (Sueur et al., 2008a, 2014; Pieretti et al., 2011) and have been correlated with important ecological variables such as biodiversity and habitat complexity (Sueur et al., 2008a; Farina et al., 2011; Depraetere et al., 2012; Gasc et al., 2013; Fuller et al., 2015).

Marine ecologists have begun to apply these metrics to underwater sound recordings; however, it remains unclear if this approach provides ecological information beyond what can be extracted from more traditional sound pressure level and spectral analyses (Kaplan et al., 2017; Staaterman et al., 2017). Differences between marine and terrestrial soundscapes have been largely ignored in adopting these metrics (Blondel and Hatta, 2017). For example, marine soundscapes are often dominated by the extremely broadband $(\sim 0.2$ to several 10 's $\mathrm{kHz}$ ) signals associated with aggregations of snapping shrimp (Au and Banks, 1998; Lammers et al., 2008; Bohnenstiehl et al., 2016; Butler et al., 2017), for which there is no equivalent terrestrial source. In addition, while terrestrial species often partition their use of the soundscape (Krause, 1993; Medeiros et al., 2017), calls from different fish species tend to overlap within a relatively narrow (1-3 kHz wide) band, which may at times be dominated by intense chorusing (Luczkovich et al., 2008; Wall et al., 2013; Montie et al., 2015; Ricci et al., 2016, 2017; Rice et al., 2017; Staaterman et al., 2017).

Here we review two soundscape indices frequently used to assess biodiversity in marine habitats, the Acoustic Complexity Index (ACI) and Acoustic Entropy $(\mathrm{H})$, with the aim of assessing their effectiveness and potential shortcomings. Both field and synthetic soundscape recordings are used to investigate the sensitivity of ACI and $\mathrm{H}$ to changes in the rate and composition of biological sound production. Based on our review of the marine soundscape literature and the results of this analysis, we conclude with recommendations for the use of these acoustic metrics to assess marine ecosystems.

\section{Background and review}

\section{Acoustic Complexity Index (ACI)}

The Acoustic Complexity Index (ACI) estimates the complexity of an acoustic recording in space and time (Farina and Morri, 2008; Pieretti et al., 2011). In its development for terrestrial environments, the ACI was designed to be minimally affected by sustained sounds (i.e., background noise) that have small amplitude variation over time, and generate higher values when more variable transient biological sounds were present in a recording.

Consider a spectrogram generated from a recording, with $n$ non-overlapping time steps and $m$ frequency bins. The ACI is first calculated for each frequency bin ( $i$ ) by summing the absolute difference in intensity between adjacent time steps $(k)$ and normalizing this total by the sum of intensity in that frequency bin. These values are then summed across all frequency bins:

$$
\mathrm{ACI}=\sum_{i=1}^{m} \frac{\sum_{k=1}^{n}\left|I_{i k}-I_{i k+1}\right|}{\sum_{k=1}^{n} I_{i k}}
$$

In practice, the length of the recording segment is selected by the end-user, with values commonly ranging from 1 to $60 \mathrm{~s}$, and the frequency range is often restricted to isolate biological sounds of interest (see Table 1 references). The number of points used in calculating the Fast Fourier Transform (NFFT) and sampling rate of the data ( $\mathrm{fs})$ determine both the frequency $(\Delta \mathrm{f}=\mathrm{fs} / \mathrm{NFFT})$ and temporal resolution $(\Delta \mathrm{T}=\mathrm{NFFT} / \mathrm{fs})$ of the analysis. Frequency resolutions of $25-100 \mathrm{~Hz}$ are commonly applied (Table 1); however, this choice is rarely justified in the literature and often appears to be a consequence of selecting a default NFFT size.

Table 1 summarizes marine soundscape studies using ACI. Because the ACI is a simple summation (Eq. 1), its upper limit is unbound and its value will depend on the length of the data segment analyzed and the chosen time-frequency resolution (i.e., the number of bins within the length of the recording segment). The maximum percent range of variation in ACI, as opposed to its absolute value, is therefore reported (Table 1) in order to make meaningful comparisons. 
Table 1. Summary of $\mathrm{ACl}$ results from marine soundscape studies.

\begin{tabular}{|c|c|c|c|c|}
\hline Study (system) & $\Delta f$ & Freq. band & $\begin{array}{l}\text { Max. } \\
\text { variation }\end{array}$ & Observation \& correlations \\
\hline $\begin{array}{l}\text { McWilliam and } \\
\text { Hawkins, } 2013 \\
\text { (temperate inlet) }\end{array}$ & $187.5 \mathrm{~Hz}$ & $2.0-4.0 \mathrm{kHz}$ & 80\% & $\begin{array}{l}\text { Possitively correlated with snap } \\
\text { count; Not correlated with } \\
\text { species assemblages or habitat } \\
\text { characteristics; } \\
\text { Sensitive to anthropogenic noise }\end{array}$ \\
\hline $\begin{array}{l}\text { Staaterman et al., } \\
2014 \text { (sub-tropical } \\
\text { coral reef) }\end{array}$ & $25.0 \mathrm{~Hz}$ & $0.001-10.0 \mathrm{kHz}$ & 12\% & $\begin{array}{l}\text { Diel patterns; Tightly correlated } \\
\text { with snapping activity }(\mathrm{HB})\end{array}$ \\
\hline $\begin{array}{l}\text { Desjonquères et al., } \\
2015 \text { (temperate } \\
\text { pond) }\end{array}$ & $86.0 \mathrm{~Hz}$ & $0.1-22.0 \mathrm{kHz}$ & --- & $\begin{array}{l}\text { Positively correlated with richness } \\
\text { and abundance of sound types }\end{array}$ \\
\hline $\begin{array}{l}\text { Kaplan et al., } 2015 \\
\text { (tropical coral reef) }\end{array}$ & $50 \mathrm{~Hz}$ & $0.1-20.0 \mathrm{kHz}$ & -- & $\begin{array}{l}\text { No correlation with species } \\
\text { assemblage or trends in low } \\
\text { frequency SPL }\end{array}$ \\
\hline $\begin{array}{l}\text { Harris et al., 2016* } \\
\text { (temperate rocky } \\
\text { reef) }\end{array}$ & $281.3 \mathrm{~Hz}$ & $0.1-24.0 \mathrm{kHz}$ & $\sim 37 \%$ & $\begin{array}{l}\text { Positive correlation with Pielou's } \\
\text { Evenness }\left(\mathrm{J}^{\prime}\right) \text { and Shannon's } \\
\text { Index }\left(\mathrm{H}^{\prime}\right)\end{array}$ \\
\hline \multirow[t]{2}{*}{$\begin{array}{l}\text { Bertucci et al., } 2016 \\
\text { (tropical coral reef) }\end{array}$} & \multirow[t]{2}{*}{$39.1 \mathrm{~Hz}$} & $\begin{array}{l}0.02-2.0 \mathrm{kHz} \\
\left(\mathrm{LB}^{+}\right)\end{array}$ & $\begin{array}{l}\sim 6.6 \% \\
(\mathrm{LB})\end{array}$ & Diel patterns; \\
\hline & & $\begin{array}{l}2.0-20.0 \mathrm{kHz} \\
\left(\mathrm{HB}^{+}\right)\end{array}$ & $\begin{array}{l}\sim 16.7 \% \\
(\mathrm{HB})\end{array}$ & $\begin{array}{l}\text { Positive correlation with number } \\
\text { of species (LB) and } \\
\text { Shannon-Wiener fish diversity } \\
\text { index (LB and HB); Higher in MPA } \\
\text { reef than non-MPA reef }\end{array}$ \\
\hline $\begin{array}{l}\text { Butler et al., } 2016 \\
\text { (subtropical coast) }\end{array}$ & $46.9 \mathrm{~Hz}$ & $0.01-24.0 \mathrm{kHz}$ & $\sim 13 \%$ & $\begin{array}{l}\text { Diel patterns driven by snaps; } \\
\text { Slightly higher in non-degraded } \\
\text { habitats, but no significant } \\
\text { difference with habitat type. }\end{array}$ \\
\hline \multirow{2}{*}{$\begin{array}{l}\text { Buscaino et al., } 2016 \\
\text { (Mediterranean } \\
\text { rocky-reef) }\end{array}$} & $22.2 \mathrm{~Hz}$ & $\begin{array}{l}0.125-0.5 \mathrm{kHz} \\
(\mathrm{LB})\end{array}$ & $\begin{array}{l}\sim 25 \% \\
\text { (LB) }\end{array}$ & \multirow{2}{*}{$\begin{array}{l}\text { Positively correlated with fish } \\
\text { sound count (LB) and snap count } \\
\text { (HB) }\end{array}$} \\
\hline & & $\begin{array}{l}4.0-64.0 \mathrm{kHz} \\
(\mathrm{HB})\end{array}$ & $\begin{array}{l}\sim 70 \% \\
(\mathrm{HB})\end{array}$ & \\
\hline $\begin{array}{l}\text { Picciulin et al. } 2016 \\
\text { (shallow, temperate } \\
\text { coast) }\end{array}$ & $86.1 \mathrm{~Hz}$ & $0.05-1.082 \mathrm{kHz}$ & $\sim 125 \%$ & $\begin{array}{l}\text { Positively correlated with fish } \\
\text { chorusing; differed over time but } \\
\text { not between sites }\end{array}$ \\
\hline $\begin{array}{l}\text { Bolgan et al., } 2017 \\
\text { (temperate lakes/ } \\
\text { rivers) }\end{array}$ & $39.1 \mathrm{~Hz}$ & $0.46-6.0 \mathrm{kHz}$ & $\sim 16 \%$ & $\begin{array}{l}\text { Positively correlated with gravel } \\
\text { noise during spawning and fish } \\
\text { air passage noise; } \\
\text { Diel patterns associated with } \\
\text { insect calls }\end{array}$ \\
\hline $\begin{array}{l}\text { Pieretti et al., } 2017 \\
\text { (Mediterranean Sea) }\end{array}$ & $\begin{array}{l}39.1 \mathrm{~Hz} \\
(\mathrm{LB})\end{array}$ & $0-0.62 \mathrm{kHz}(\mathrm{LB})$ & $\begin{array}{l}\sim 23 \% \\
(\mathrm{LB})\end{array}$ & $\begin{array}{l}\text { Tracks fish chorusing, but delayed } \\
\text { increase following onset of }\end{array}$ \\
\hline
\end{tabular}


Table 1. Continued

\begin{tabular}{|c|c|c|c|c|}
\hline Study (system) & $\Delta f$ & Freq. band & $\begin{array}{l}\text { Max. } \\
\text { variation }\end{array}$ & Observation \& correlations \\
\hline & $\begin{array}{l}312.5 \mathrm{~Hz} \\
(\mathrm{HB})\end{array}$ & $\begin{array}{l}0.62-40.0 \mathrm{kHz} \\
(\mathrm{HB})\end{array}$ & $\begin{array}{l}\sim 45 \% \\
(\mathrm{HB})\end{array}$ & $\begin{array}{l}\text { chorusing (LB); Diel patterns } \\
\text { associated with snaps (HB). }\end{array}$ \\
\hline $\begin{array}{l}\text { Rice et al. } 2017 \\
\text { (temperate offshore } \\
\text { habitat) }\end{array}$ & $3.9 \mathrm{~Hz}$ & $0-1.0 \mathrm{kHz}$ & 10\% & $\begin{array}{l}\text { Diel patterns; } \\
\text { Increased during periods of } \\
\text { intense chorusing by black drum; } \\
\text { Sensitive to anthropogenic noise }\end{array}$ \\
\hline \multirow[t]{2}{*}{$\begin{array}{l}\text { Staaterman et al., } \\
2017 \text { (tropical coast) }\end{array}$} & $50 \mathrm{~Hz}$ & $\begin{array}{l}0.025-1.0 \mathrm{kHz} \\
\text { (LB) }\end{array}$ & $\begin{array}{l}\sim 40 \% \\
(\mathrm{LB})\end{array}$ & \multirow{2}{*}{$\begin{array}{l}\text { No significant differences } \\
\text { between habitats (LB and HB); } \\
\text { Drops during periods of intense } \\
\text { chorusing by Bocon Toadfish } \\
\text { (LB); Indicator of snap production } \\
\text { (HB). }\end{array}$} \\
\hline & & $\begin{array}{l}3.0-10.0 \mathrm{kHz} \\
(\mathrm{HB})\end{array}$ & $\begin{array}{l}\sim 50 \% \\
(\mathrm{HB})\end{array}$ & \\
\hline
\end{tabular}

*The $\mathrm{ACl}$ routine in the Seewave R Package (V. 2.0.5 and earlier; Sueur et al., 2008b) did not pass the user-defined NFFT sizes to the spectrogram function, and consequently all $\mathrm{ACl}$ values reported in Harris et al. (2016) used NFFT $=512(\Delta \mathrm{f}=281.3 \mathrm{~Hz})$.

${ }^{+} \mathrm{LB}=$ low band; $\mathrm{HB}=$ high band.

Two marine soundscape studies have shown a correlation between ACI and fish survey data. Within temperate reef systems in New Zealand, Harris et al. (2016) reported that ACI was positively correlated with Pielou's Evenness and Shannon's Index. For a south-Pacific reef system, Bertucci et al. (2016) showed that ACI increased with the number of species and the Shannon-Wiener fish diversity index. Similarly, the richness of sound types was correlated with ACI in temperate ponds in France (Desjonquères et al., 2015). While these results suggest that ACI may respond positively to an increase in acoustic diversity, these patterns are not universal (e.g., Kaplan et al., 2015; Butler et al. 2016) and other work has suggested that ACI can be influenced strongly by the rate of sound production associated with a single, or small number of species. Several papers, for example, have noted changes in ACI modulated by the broadband signals associated with snapping shrimp (e.g., McWilliam and Hawkins, 2013; Staaterman et al., 2014; Kaplan et al., 2015; Butler et al., 2016; Buscaino et al., 2016). Others have shown that ACI varies temporally in response to fish chorusing (i.e., the number of calls) (Desjonquères et al., 2015; Buscaino et al., 2016; Rice et al., 2017) and that the abundance of sounds produced by a single fish species can have a direct effect on ACI (Bolgan et al., 2017; Staaterman et al., 2017).

\section{Acoustic Entropy $(\mathrm{H})$}

Acoustic Entropy H, developed by Sueur et al. (2008a), attempts to quantify the average diversity within an acoustic community. $\mathrm{H}$ is calculated following the Shannon diversity index in ecology, which increases with species richness and evenness. Similarly, acoustic entropy is purported to increase with the number of vocalizing species and evenness of the acoustic environment (Sueur et al., 2008a).

Acoustic entropy is comprised of both temporal and spectral entropy. Temporal entropy calculates the evenness of a signal's amplitude over time. Thus, for any given time series $x(t)$ of length $n$, temporal entropy is calculated using:

$$
H_{t}=-\sum_{t=1}^{n} A(t) \times \log _{2} A(t) \times \log _{2}(n)^{-1}
$$

where $A(t)$ is the probability mass function of the amplitude envelope in the time domain. In practice, the signal is band-pass filtered to isolate biological signals prior to being enveloped. The time series segment length must be defined by the end-users, with values between 5 and $60 \mathrm{~s}$ commonly applied (Table 2 references). Spectral entropy calculates the evenness of a signal's frequency-amplitude spectrum:

$$
H_{f}=-\sum_{f=1}^{N} S(f) \times \log _{2} S(f) \times \log _{2}(N)^{-1}
$$

where $S(f)$ is the probability mass function calculated from the mean spectrum having $\mathrm{N}$ frequency bins. The 
Table 2. Summary of $\mathrm{H}$ results from marine soundscape studies.

\begin{tabular}{|c|c|c|c|c|}
\hline Study & $\Delta f$ & Freq. band & Max. range & Observation and correlations \\
\hline \multirow[t]{2}{*}{$\begin{array}{l}\text { Denes et al., } 2014 \\
\text { (Bering Sea) }\end{array}$} & \multirow[t]{2}{*}{---} & $\begin{array}{l}0.1-50 \mathrm{kHz} \text { (high } \\
\text { sample rate } \\
\text { recorders) }\end{array}$ & $0.22-0.58$ & $\begin{array}{l}\text { No significant relationship with } \\
\text { counts of marine mammals; } \\
\mathrm{H}_{\mathrm{t}} \text { positively related to species } \\
\text { richness; }\end{array}$ \\
\hline & & $\begin{array}{l}0.1-4.1 \mathrm{kHz} \text { (low } \\
\text { sample rate } \\
\text { recorders) }\end{array}$ & $0.70-0.95$ & $\begin{array}{l}\text { Sensitive to anthropogenic } \\
\text { noise }\end{array}$ \\
\hline $\begin{array}{l}\text { Lillis et al., } 2014 \\
\text { (temperate estuary) }\end{array}$ & $93.8 \mathrm{~Hz}$ & $0.1-24 \mathrm{kHz}$ & $0.50-0.9$ & $\begin{array}{l}\text { Higher at oyster reef sites than } \\
\text { soft bottom sites, driven by } \\
\text { snapping activity }(\mathrm{HB})\end{array}$ \\
\hline $\begin{array}{l}\text { Parks et al., } 2014 \\
\text { (South Atlantic, } \\
\text { North Pacific, and } \\
\text { Indian Oceans) }\end{array}$ & $0.25 \mathrm{~Hz}$ & $1-125 \mathrm{~Hz}$ & $0.88-0.94$ & $\begin{array}{l}\text { Does not correspond to } \\
\text { biological patterns inferred } \\
\text { from marine mammal call } \\
\text { detections and classification; } \\
\text { Sensitive to anthropogenic } \\
\text { noise }\end{array}$ \\
\hline \multirow[t]{3}{*}{$\begin{array}{l}\text { Kaplan et al., } 2015 \\
\text { (tropical coral reef) }\end{array}$} & \multirow[t]{3}{*}{$50.0 \mathrm{~Hz}$} & $0.1-1.0 \mathrm{kHz}(\mathrm{LB})$ & $\begin{array}{l}0.70-0.98 \\
(\mathrm{LB})\end{array}$ & \multirow{3}{*}{$\begin{array}{l}\text { Differences between habitats, } \\
\text { but results not correlated with } \\
\text { visual fish and habitat survey } \\
\text { data (LB); Trend driven by } \\
\text { snapping shrimp (HB and FB). }\end{array}$} \\
\hline & & $2.0-20.0 \mathrm{kHz}(\mathrm{HB})$ & $\begin{array}{l}0.85-0.95 \\
(\mathrm{HB})\end{array}$ & \\
\hline & & $0.1-20.0 \mathrm{kHz}(\mathrm{FB})$ & $\begin{array}{l}0.85-0.95 \\
(\mathrm{FB})\end{array}$ & \\
\hline \multirow{4}{*}{$\begin{array}{l}\text { Harris et al., } 2016 \\
\text { (temperate rocky } \\
\text { reef) }\end{array}$} & $281.3 \mathrm{~Hz}$ & \multirow[t]{4}{*}{$0.1-24.0 \mathrm{kHz}$} & $0.71-0.75$ & \multirow{4}{*}{$\begin{array}{l}\text { Positive correlation with } \\
\text { number of species \& } \\
\text { Shannon's Index }\left(\mathrm{H}^{\prime}\right) \text { for } \Delta \mathrm{f} \leq \\
140.6 \mathrm{~Hz} \text {; Robust to } \\
\text { anthropogenic noise }\end{array}$} \\
\hline & $140.6 \mathrm{~Hz}$ & & $0.80-0.86$ & \\
\hline & $70.3 \mathrm{~Hz}$ & & $0.80-0.86$ & \\
\hline & $35.1 \mathrm{~Hz}$ & & $0.80-0.86$ & \\
\hline $\begin{array}{l}\text { Rice et al. } 2017 \\
\text { (temperate offshore } \\
\text { habitat) }\end{array}$ & $3.9 \mathrm{~Hz}$ & $0-1.0 \mathrm{kHz}$ & $0.75-0.95$ & $\begin{array}{l}\text { Increased at onset of fish } \\
\text { chorusing (LB); Diel patterns }\end{array}$ \\
\hline \multirow[t]{2}{*}{$\begin{array}{l}\text { Staaterman et al., } \\
2017 \text { (tropical coast) }\end{array}$} & \multirow[t]{2}{*}{$50.0 \mathrm{~Hz}$} & $0.025-1.0 \mathrm{kHz}(\mathrm{LB})$ & $\begin{array}{l}0.2-0.6 \\
(\mathrm{LB})\end{array}$ & \multirow{2}{*}{$\begin{array}{l}\text { Significantly higher in reefs } \\
\text { and sand than in mangroves } \\
\text { (LB); Drops during periods of } \\
\text { intense chorusing by Bocon } \\
\text { Toadfish (LB). Modulated by } \\
\text { snapping, but with no } \\
\text { significant differences based } \\
\text { on habitat (HB). }\end{array}$} \\
\hline & & $3.0-10.0 \mathrm{kHz}(\mathrm{HB})$ & $\begin{array}{l}0.75-0.9 \\
(\mathrm{HB})\end{array}$ & \\
\hline
\end{tabular}

$\mathrm{LB}=$ low band $\mathrm{HB}=$ high band; $\mathrm{FB}=$ full band 
spectral resolution of the analysis is controlled by the user's choice of NFFT length $(\Delta f=f s / N F F T)$. The total acoustic entropy index $(\mathrm{H})$ is derived from the product of spectral and temporal entropy:

$$
H=H_{t} \times H_{f}
$$

$\mathrm{H}$ will approach 0 for a single pure tone, increase with the number of amplitude modulations and frequency bands in a time series, and approach 1 for completely random noise (Sueur et al., 2008a).

Table 2 summarizes marine soundscape studies using H. For temperate reef systems in New Zealand, Harris et al. (2016) showed that the acoustic entropy was correlated with number of species and Shannon's Index $\left(\mathrm{H}^{\prime}\right)$ when a spectral resolution finer than $140.6 \mathrm{~Hz}$ was used in the analysis. Other studies have shown significant differences in $\mathrm{H}$ between habitat types; however, as with $\mathrm{ACI}$, most authors have attributed these differences to variable rates of sound production by snapping shrimp (Lillis et al., 2014; Kaplan et al., 2015; Staaterman et al., 2017). or a single species of fish (Staaterman et al., 2017; Rice et al., 2017).

\section{Field recordings of single call type soundscapes}

There is increasing evidence that variations in the rate of biological sound production may play a key role in modulating ACI and $\mathrm{H}$ in marine soundscapes (e.g., McWilliam and Hawkins, 2013; Kaplan et al., 2015; Butler et al., 2016; Buscaino et al., 2016; Staaterman et al., 2017). To evaluate this further, H and ACI were calculated within two single-call-type-dominated marine soundscapes: a tropical back-reef ecosystem where the highfrequency soundscape is modulated by the broadband impulsive sounds of invertebrate snapping shrimp, and a mid-Atlantic estuary where the low-frequency soundscape is modulated by harmonic boatwhistle calls of oyster toadfish (Opsanus tau). Based on our review of the literature (Tables 1 and 2), we hypothesize that ACI and $\mathrm{H}$ may be sensitive to (1) call rate, (2) call type and (3) the time-frequency resolution specified in the analysis.

\section{Snap dominated soundscapes}

As part of a study examining tropical back-reef nursery habitats, the soundscapes of seven concrete block experimental patch reefs within the Bight of Old Robinson (Abaco Island, The Bahamas) were recorded between March and July 2016. Underwater sound was recorded ( $f s=96 \mathrm{kHz}$ ) concurrently at each patch reef for 2 min

a

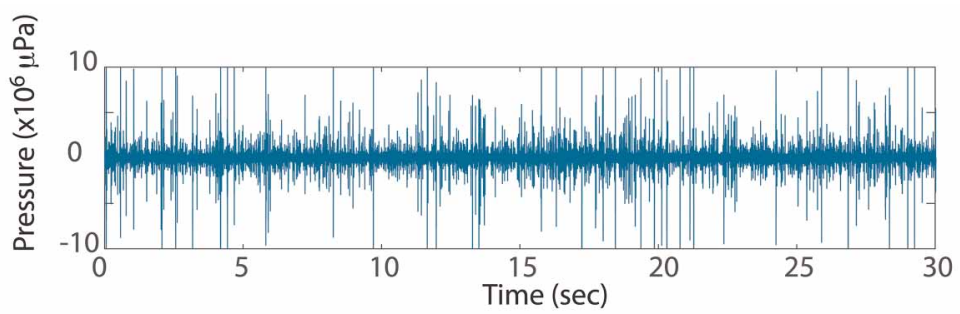

b

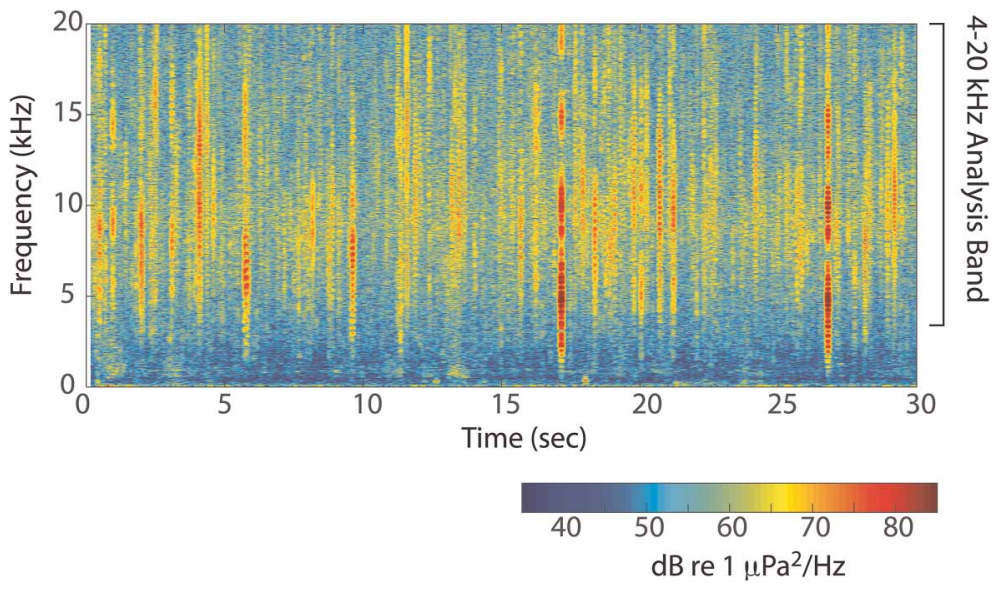

Figure 1. Example of snap dominated backreef soundscape recorded in July of 2016 within the Bight of Old Robinson, Abaco Island, The Bahamas.

(a) Time series of acoustic pressure. (b) Spectrogram generated using NFFT $=2^{15}$ points $(\Delta f=2.93 \mathrm{~Hz})$ with $95 \%$ overlap. The snap rate for this recording period was estimated to be 2728 snaps $/ \mathrm{min}$. 
every 20 min using a set of SoundTrap 300 recorders (Ocean Instruments NZ). The hydrophones were positioned $\sim 1 \mathrm{~m}$ away from each patch reef, $\sim 0.5 \mathrm{~m}$ above the seabed and approximately 1.4-3.8 m below mean lower low water (MLLW) level at all sites.

These patch reefs were inhabited principally by juvenile and sub-adult fish, so fish vocalizations were rare and chorusing absent within these back-reef habitats (Lyon, 2018). The soundscape, particularly at higher frequencies, was instead dominated by the short-duration impulse signals produced by resident snapping shrimp (Figure 1). To estimate the rate of snapping in each recording, these signals were detected using an envelope correlation and amplitude threshold method developed by Bohnenstiehl et al. (2016). The snap detection procedure operated in the 4-20 kHz frequency band, where these acoustic arrivals exhibited the highest signal levels relative to ambient background noise (Figure 1). We set a correlation coefficient cutoff of 0.70 and a $102 \mathrm{~dB}$ re $1 \mu \mathrm{Pa}$ (peak-to-peak) amplitude threshold, which corresponds to the $90 \%$ quantile of the background sound levels observed throughout the recording period. The detection kernel was derived from the local recordings and leftpadded to suppress the possible detection of sea surface reflected arrivals at short time delays.

Because the rate of snapping varies temporally in response to changes in temperature, light and other environmental variables (e.g., Watanabe et al., 2002; Jung et al., 2012; Bohnenstiehl et al., 2016; Lillis et al., 2017), these data can be used to investigate the response of the acoustic metrics to variations in the rate of broadband snapping activity. Both $\mathrm{ACI}$ and $\mathrm{H}$ were calculated in the $4-20 \mathrm{kHz}$ frequency band using a $30 \mathrm{~s}$ analysis time window. ACI and $\mathrm{H}_{\mathrm{f}}$ were estimated using variable NFFT sizes of 1024, 2048 and 4096 points; $\mathrm{H}_{\mathrm{t}}$ was estimated from the envelope of the band-passed (5th order Butterworth) waveform. This procedure was applied in four non-overlapping time windows and the results were averaged for each 2-min duration recording.

The sensitivity of $\mathrm{H}$ and $\mathrm{ACI}$ to variation in snap rate is illustrated in Figure 2 using data from experimental reef $\# 7\left(26.339^{\circ} \mathrm{N}, 77.018^{\circ} \mathrm{W}\right)$ within the Bight of Old Robinson (Lyon, 2018). As expected, the absolute value
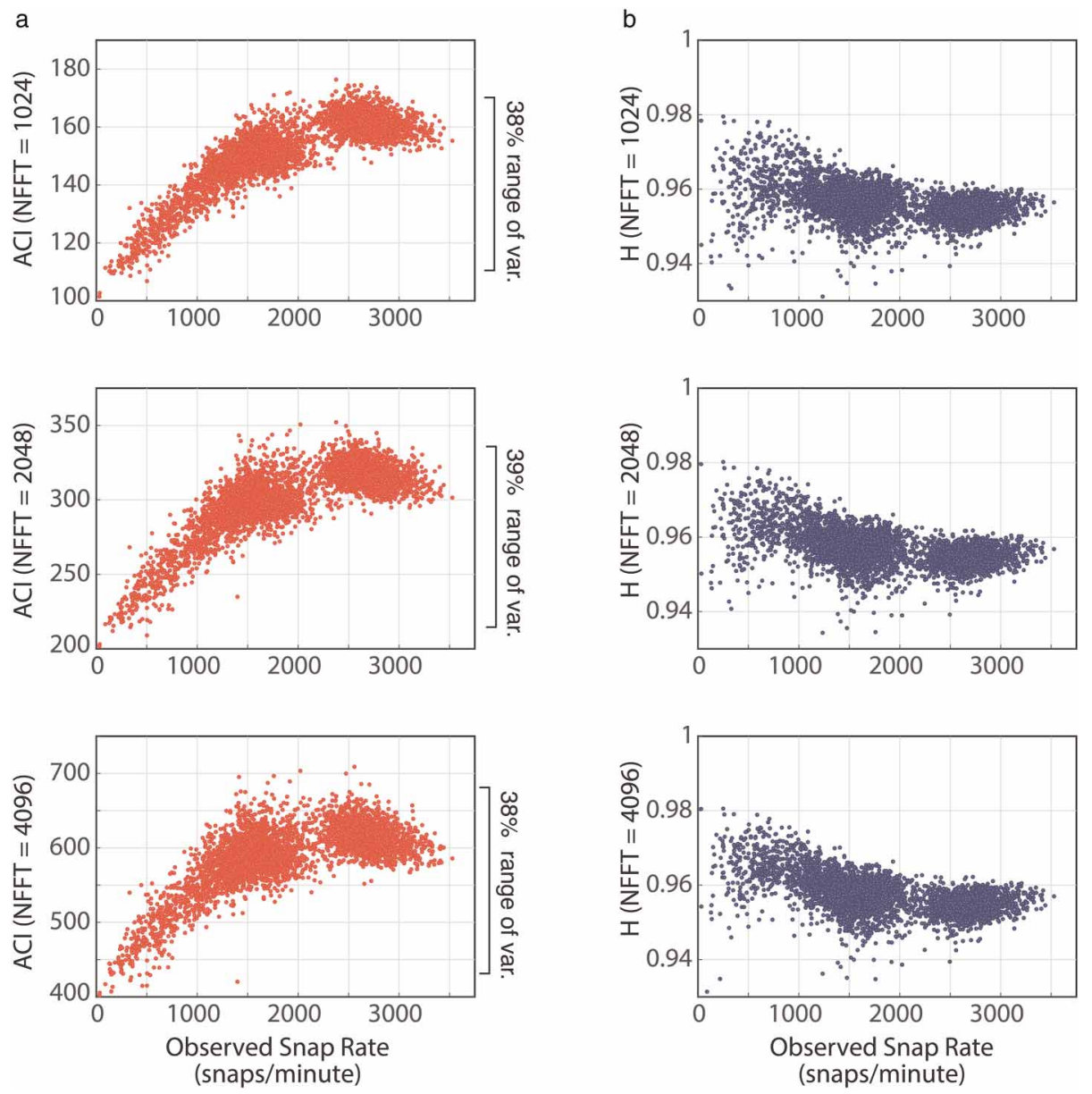

Figure 2. Variations in (a) $\mathrm{ACl}$ and (b) $\mathrm{H}$ with snap rate.

Metrics were estimated over the $4-20 \mathrm{kHz}$ band, using NFFT = 1024 ( $\Delta \mathrm{f}=93.75, \Delta \mathrm{T}=0.010 \mathrm{~s}$, top), $2048(\Delta f=46.88 \mathrm{~Hz}, \Delta \mathrm{T}=0.021 \mathrm{~s}$, middle) and $4096(\Delta f=23.43 \mathrm{~Hz}, \Delta \mathrm{T}=0.043 \mathrm{~s}$, bottom). Each point represents a single 2-min-duration recording (averaged from four 30-s duration analysis windows) taken during the deployment period in July of 2016 at reef \#7 (see Lyon, 2018) within the Bight of Old Robinson. Right bracket in (a) shows the percent variation calculated by dividing the $99 \%$ quantile range of $\mathrm{ACl}$ by its midpoint value. 
of $\mathrm{ACI}$ varied based on the spectral $(\Delta \mathrm{f}=\mathrm{fs} / \mathrm{NFFT})$ and temporal $(\Delta \mathrm{T}=\mathrm{NFFT} / \mathrm{fs})$ resolution used in the analysis; however, the range of variation over the observed range of snap rates is nearly $40 \%$ for all three cases. ACI responded non-linearly to an increased rate of snapping, rising initially but then leveling off at rates > $\sim 1000$ snaps/min. $\mathrm{H}$ values showed little-to-no sensitivity to spectral resolution. $\mathrm{H}$ decreased systematically with increasing snap rate, and although the effect was small ( $\sim 0.03$ units) it is not negligible compared to variation reported in the literature (Table 2). Since the snaps are broadband, the number of snaps had no influence on spectral entropy, and the decrease in $\mathrm{H}$ was driven instead by a drop in temporal entropy.

\section{Boatwhistle dominated soundscapes}

The Harris Creek Oyster Sanctuary is a large-scale oyster restoration project in a tributary of the Chesapeake Bay, Maryland (Paynter et al., 2012). In May of 2015, SoundTrap 300 passive acoustic recorders were deployed at eight sites (Ricci et al., 2017) that were part of a larger study evaluating ecosystem services provided by restored oyster reefs (M.L. Kellogg, VIMS, unpublished data). Acoustic data were collected for 2-min every $30 \mathrm{~min}$ at a sample rate of $96 \mathrm{kHz}$. The instruments were positioned $\sim 0.5 \mathrm{~m}$ above the seabed and approximately 1.0-3.5 m below mean lower low water (MLLW) at all sites.

Analysis of the acoustic data revealed that the low-frequency $(0.1-1.2 \mathrm{kHz})$, late-spring soundscape of these sites was dominated by a single call type: the boatwhistle sounds of the oyster toadfish, Opsanus tau (Figure 3). Snapping shrimp are not typically present within the central and northern Chesapeake Bay estuary, and although a small number of toadfish grunt sounds were identified in our recordings, the sounds produced by other fish species are largely absent during this time of the year (Ricci et al., 2017). Unlike the broadband snaps found in The Bahamas, the low-frequency boatwhistle calls are harmonic in nature, with up to four overtones commonly observed, and of much longer ( $>250 \mathrm{~ms}$ ) duration (Figure 3). Boatwhistle call frequencies are a function of water temperature; they are nearly constant within a 2 -min recording but vary on longer time scales (Tavolga, 1958; Fine, 1978; Ricci et al., 2017; Ladich, 2018).

Previously, Ricci et al. (2017) used a spectrogram correlation technique to identify boatwhistle calls within these recordings. The correlation threshold was set empirically to maintain a false positive rate of $\sim 1 \%$. The rate of boatwhistle calling increased dramatically over the first few days in May as male toadfish begin calling as an
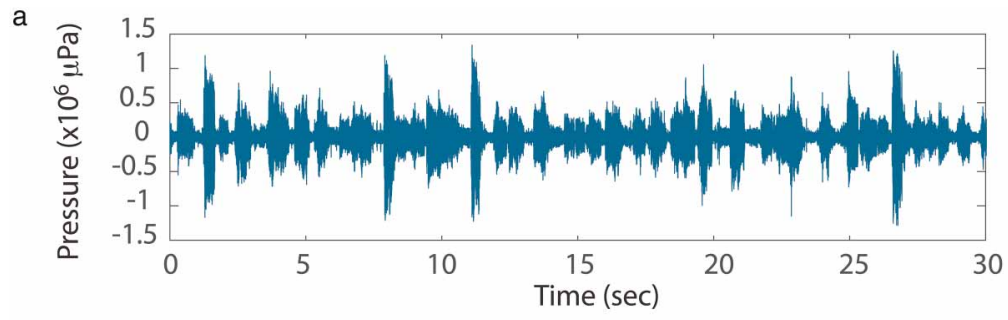

b

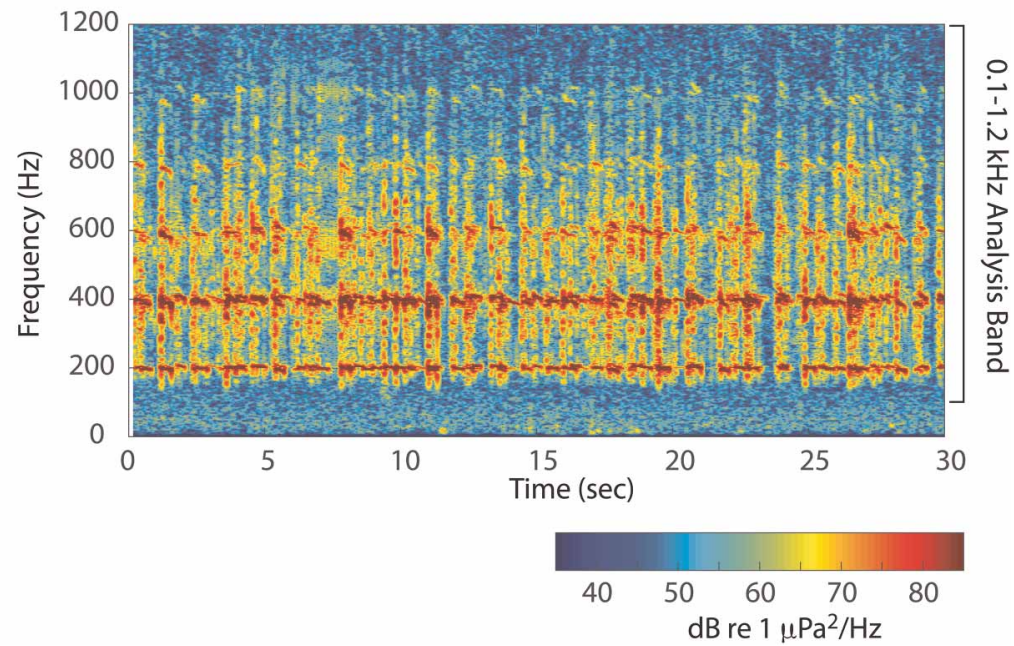

Figure 3. Example of boatwhistle dominated soundscape recorded in May of 2015 at the Little Neck Reef in Harris Creek Oyster Sanctuary.

(a) Time series of acoustic pressure. (b) Spectrogram generated using NFFT $=2^{15}$ points $(\Delta f=2.93 \mathrm{~Hz})$ with $95 \%$ overlap. The average rate of boatwhistle calls at this time was 110 calls/min. 
a
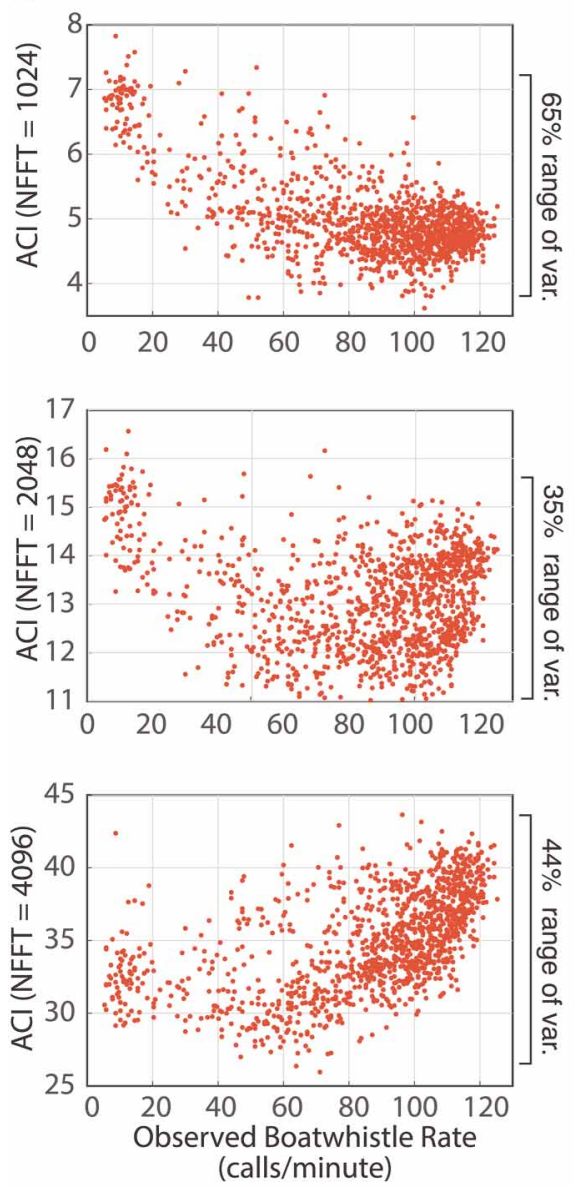

b
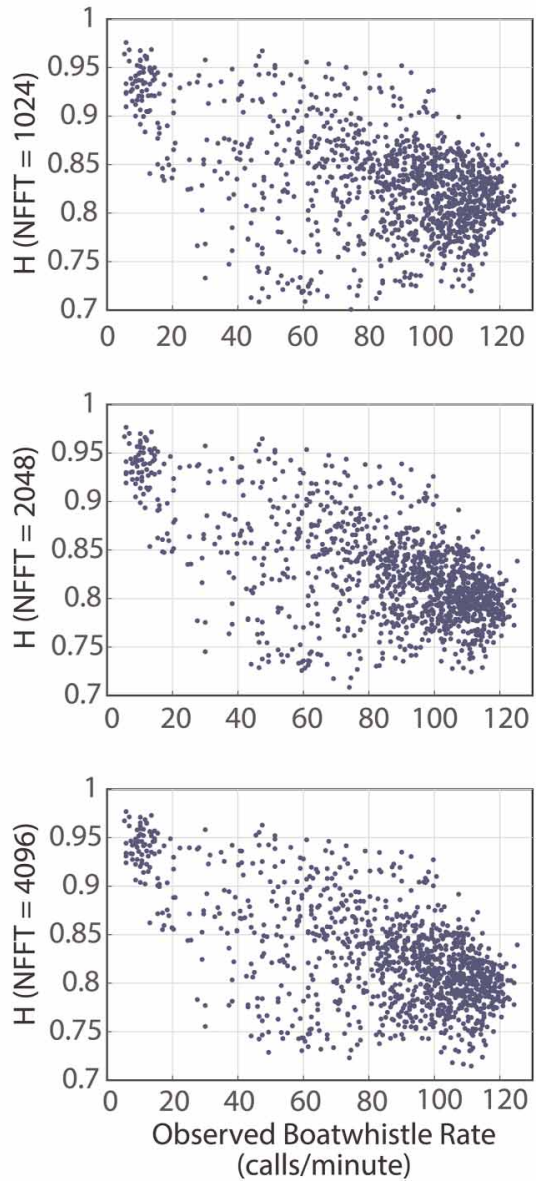

Figure 4. Variation in (a) $\mathrm{ACl}$ and (b) $\mathrm{H}$ with boatwhistle call rate.

Each point represents measurements within a single 2-min duration recording (averaged for four $30 \mathrm{~s}$ duration analysis windows) taken during the deployment period in May 2015 at the Little Neck (Ricci et al., 2017) restored oyster reef site. Metrics were estimated over the 0.1-1.2 kHz band, calculated using three different NFFT sizes: 1024 ( $\Delta \mathrm{f}=93.75, \Delta \mathrm{T}=0.010 \mathrm{~s}, \quad$ top $), 2048$ $(\Delta f=46.88 \mathrm{~Hz}, \Delta T=0.021 \mathrm{~s}$, middle), and $4096(\Delta f=23.43 \mathrm{~Hz}, \Delta \mathrm{T}=0.043 \mathrm{~s}$, bottom). Right bracket in (a) shows the percent variation calculated by dividing the $99 \%$ quantile range of $\mathrm{ACl}$ by its midpoint value.

advertisement to attract females to their nest site. These data can therefore be used to assess the response of the acoustic metrics to variations in the rate of harmonic fish sounds. Both ACI and $\mathrm{H}$ were calculated in the 0.1-1.2 kHz frequency band, where the boatwhistle overtones are dominant. Following the snapping shrimp analysis, $\mathrm{ACI}$ and $\mathrm{H}_{\mathrm{f}}$ were estimated using variable NFFT sizes; $\mathrm{H}_{\mathrm{t}}$ was calculated using the envelope of the band-passed waveform. The results from four 30-second-duration non-overlapping time windows were averaged for each 2-min recording.

The sensitivity of $\mathrm{H}$ and ACI to variation in boatwhiste call rate is illustrated in Figure 4 using data from the restored oyster reef Little Neck $\left(38.768^{\circ} \mathrm{N}, 76.296^{\circ} \mathrm{W}\right)$. The absolute value of ACI varied based on the spectral

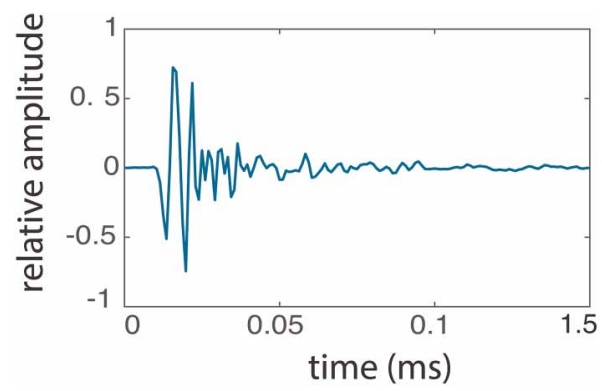

Figure 5. Time-domain representation of the snap used in the soundscape synthesis experiments.

A 5\% taper (Tukey window) was applied to the otherwise unfiltered waveform. The signal is 145 points in length and sampled at $96 \mathrm{kHz}$. 


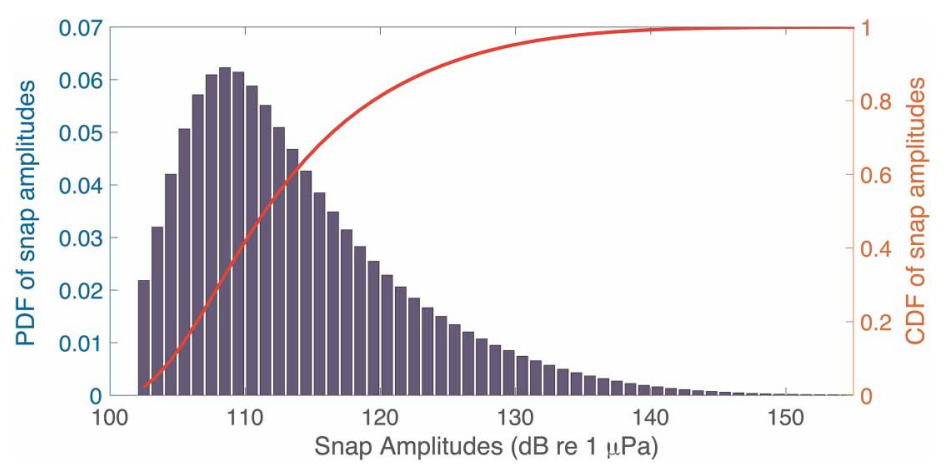

Figure 6. Empirical probability density function (PDF) and cumulative probability density function (CDF) for snap amplitudes recorded at Bight of Old Robinson reef \#7.

Snap amplitude used within the simulations were assigned randomly based on this distribution.

and temporal resolution used in the analysis. Here, the range of variation was between $35 \%$ and $65 \%$. ACI decreased non-linearly with increasing call rate for NFFT size of 1024 and 2048; however, the trend was reversed when the analysis was performed with a NFFT of 4096 points. The calculated H value again shows little-to-no sensitivity to spectral resolution; but decreased notably ( $\sim 0.20$ units) with increasing call rate (cf. Table 2$)$. This drop was driven by a decrease in the spectral component of entropy, as acoustic power becomes increasingly concentrated in the harmonic bands.

\section{Synthesis of single call type soundscapes}

To further understand the behavior of these ecoacoustic metrics, ensembles of synthetic soundscapes (e.g., Gasc et al., 2015) with known rates of calling were constructed and analyzed. Synthetic soundscapes were simulated from a single snap, or boatwhistle, that was replicated in time and mixed with constant variance background noise. Calling was assumed to be a Poisson (random) process with the distribution of received call amplitudes derived empirically from field observations.
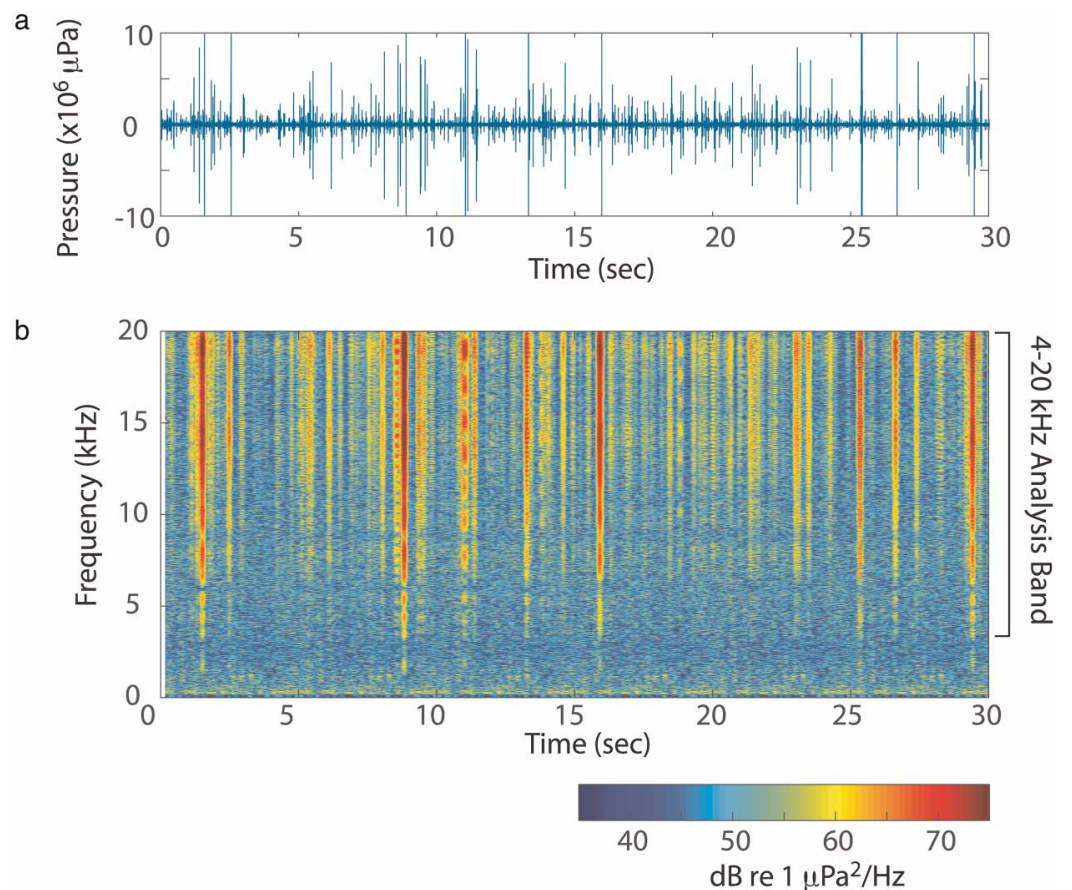

Figure 7. (a) Waveform and (b) spectrogram of a simulated snap dominated soundscape.

Snap amplitudes are drawn randomly from the empirical distribution shown in Figure 6, and snap times were assumed to follow a Poisson distribution with a mean rate of 2700 snaps/min. Spectrogram displayed using NFFT $=2^{15}$ points $(\Delta \mathrm{f}=2.93 \mathrm{~Hz})$ with $95 \%$ overlap. 
a
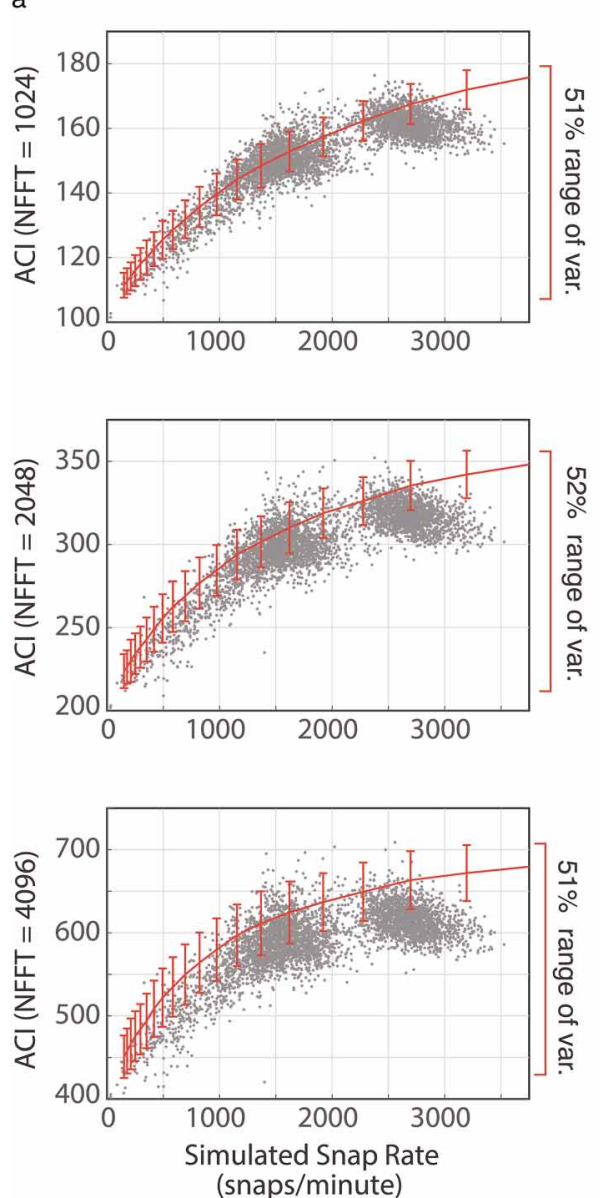

b
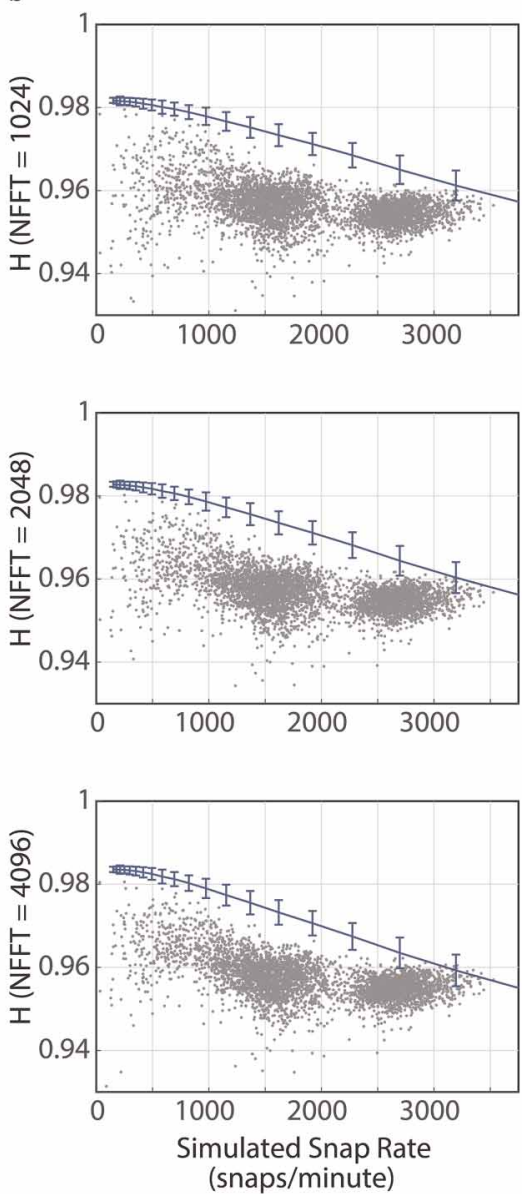

Figure 8. Variation in (a) $\mathrm{ACl}$ and (b) $\mathrm{H}$ with snap rate for the simulated soundscapes.

Solid line represents the median value based on 1000 synthetic soundscapes generated at each snap rate. Vertical error bars denote the standard deviation of these measurements. Grey dots are the field measurements from Figure 2, shown only for reference. Metrics were estimated over the $4-20 \mathrm{kHz}$ band, using NFFT $=1024(\Delta \mathrm{f}=93.75, \Delta \mathrm{T}=0.010 \mathrm{~s}$, top), $2048(\Delta f=46.88 \mathrm{~Hz}, \Delta \mathrm{T}=0.021 \mathrm{~s}$, middle), and $4096(\Delta \mathrm{f}=23.43 \mathrm{~Hz}, \Delta \mathrm{T}=0.043 \mathrm{~s}$, bottom). Right bracket in (a) denotes range of variation in the $\mathrm{ACl}$ values obtained from the synthetic soundscapes.

\section{Simulation experiments with broadband snaps}

A single snap (Figure 5) was isolated from a recording made in July 2016 within Bight of Old Robinson, The Bahamas. This signal is representative of the snaps recorded within the Bight, being impulsive in nature with rapid onset and of very short $(<1.5 \mathrm{~ms})$ duration. A $5 \mathrm{~s}$ segment lacking discernible snaps also was identified to populate the background noise field. Each simulation produced a $30 \mathrm{~s}$ duration synthetic recording, for which background noise was prescribed by looping this recording. Snaps were superimposed within this background. The time of each snap was selected randomly assuming a Poisson distribution for the inter-snap times, with snaps overlapping when small inter-snap times were drawn. Snap rates between 100 and 3500 snaps/min were considered, with 1000 simulations conducted at each snap rate. The amplitude of each snap was randomly drawn from the population of snap amplitudes recorded over the course of two months of monitoring within the Bight of Old Robinson (Figure 6). An example of the resulting simulated soundscape is shown in Figure 7.

Each $30 \mathrm{~s}$ simulation was analyzed in the $4-20 \mathrm{kHz}$ range following the procedure used to assess the field recordings, with NFFT window lengths of $1024(\Delta \mathrm{f}=93.75 \mathrm{~Hz}, \Delta \mathrm{T}=0.010 \mathrm{~s}), 2048(\Delta \mathrm{f}=46.88 \mathrm{~Hz}$, $\Delta \mathrm{T}=0.021)$ and $4096(\Delta \mathrm{f}=23.44, \Delta \mathrm{T}=0.043)$ points. As expected, the absolute value of ACI varied with changing NFFT window length, but the results show a similar pattern for each set of simulations (Figure 8a). ACI initially increased with increasing snap rate, exhibiting a $\sim 50 \%$ range of variability, but then leveled off at with higher snap rates. The acoustic entropy shows a small decrease with increasing snap rate (Figure $8 \mathrm{~b}$ ). The patterns produced by these simple simulations mirror those observed in the field records. 


\section{Simulation experiments with boatwhistles}

A single boatwhistle (Figure 9) was isolated from a recording made during May 2015 within Harris Creek, Maryland. The selected signal is $350 \mathrm{~ms}$ in length. A 5 s segment lacking discernible transient calls and with relatively low noise $(87.3 \mathrm{~dB}$-rms re $1 \mu \mathrm{Pa}$ ) also was identified to seed the background sound field. As was the case in the snap simulations, each boatwhistle simulation produced a $30 \mathrm{~s}$ synthetic recording, for which background noise was prescribed by looping this recording. Boatwhistle arrivals were superimposed randomly within this background. Vocalization scenarios with rates between 6 and $120 \mathrm{call} / \mathrm{min}$ were considered, with 1000 simulations conducted at each call rate. The amplitude of each call was randomly assigned based on the distribution of received call amplitudes observed in the field data (Figure 10). An example of a simulated boatwhistledominated soundscape is shown in Figure 11.

Each 30-s duration boatwhistle simulation was analyzed in the $0.1-1.2 \mathrm{kHz}$ range using NFFT sizes of 1024, 2048 and 4096 (Figure 12). Consistent with the field observations, these simulations indicated that the response of ACI to boatwhistle call rate was dependent on the NFFT size chosen for the analysis. ACI decreased with increasing call rate when a coarse (NFFT 1024 and 2048) spectral resolution was used; but, it increased with increasing call rate when assessed using a finer spectral resolution (NFFT 4096). Driven by a decrease in spectral entropy, $\mathrm{H}$ decreased by $\sim 0.2$ units as boatwhistle rate increased. This pattern showed no dependence on spectral resolution. At a given call rate, the variability in ACI and $\mathrm{H}$ predicted by these synthesis experiments was less than that observed in the Harris Creek field recordings (Figure 12).

\section{Discussion}

In this study, both $\mathrm{H}$ and ACI were found to be sensitive to call rate and call type. For soundscapes dominated by impulsive broadband snapping, ACI initially increased with increased snapping, but the response saturated at high snap rates (Figures $2 \mathrm{a}$ and $8 \mathrm{a}$ ). When snap rates varied between $\sim 100$ to $3500 \mathrm{snaps} / \mathrm{min}$, a $\sim 40 \%$ and $\sim 50 \%$ range of variation in ACI was observed within the field and simulated datasets, respectively. The spectral resolution influenced the absolute value of ACI, but not the observed trends or percent range of variation in the snap dominated soundscape (Figure 13a). For soundscapes dominated by longerduration harmonic boatwhistle calls, ACI decreased with increased calling rates when the spectral resolution

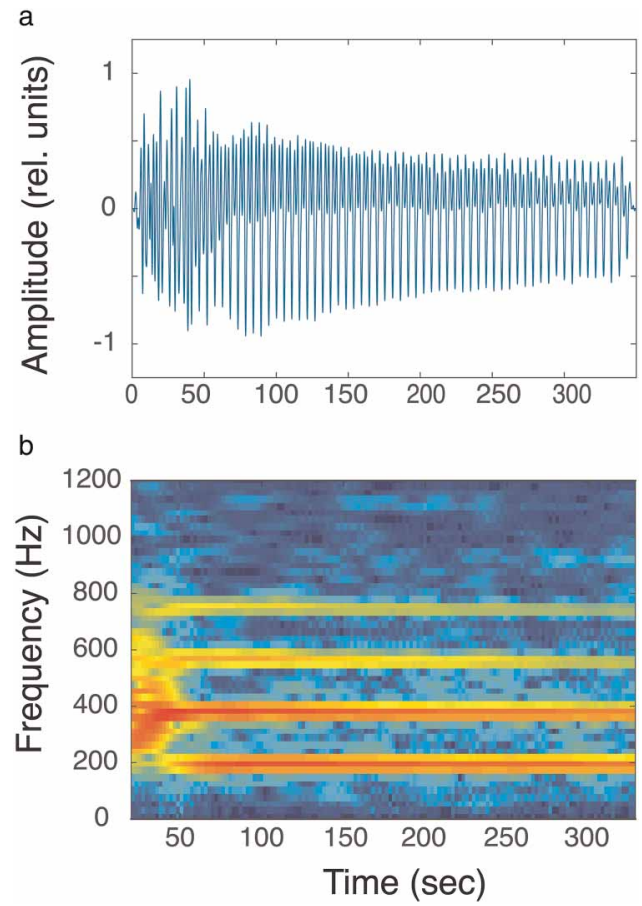

Figure 9. (a) Acoustic waveform of the boatwhistle used in the simulations. A 5\% taper (Tukey window) was applied to the otherwise unfiltered waveform. The signal is 33600 points in length and sampled at $96 \mathrm{kHz}$; (b) lowfrequency spectrogram of this signal produced using an NFFT of 4096 points with $95 \%$ overlap. 


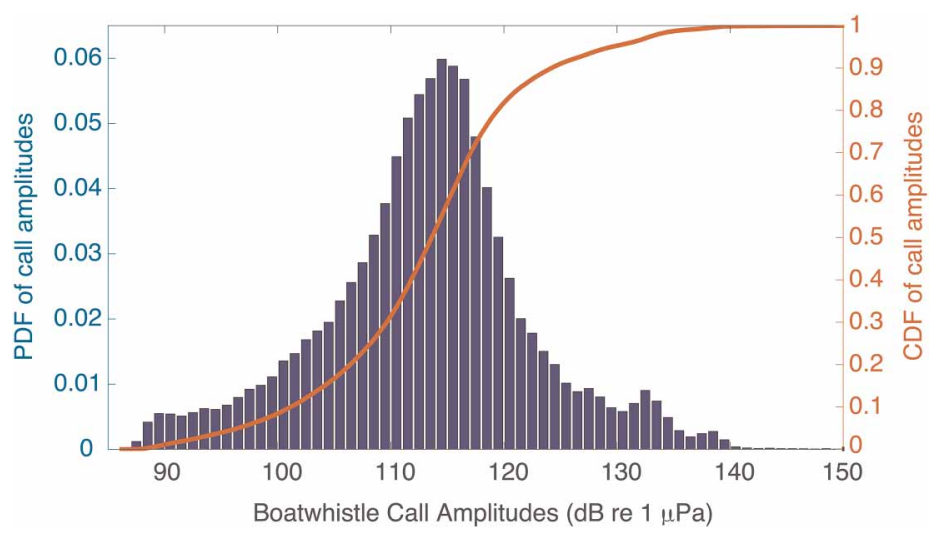

Figure 10. Empirical probability density function (PDF) and cumulative probability density function (CDF) for boatwhistle amplitudes recorded at restored reef Little Neck.

Call amplitudes used within the simulations were assigned randomly based on this distribution.

was coarse $(\Delta \mathrm{f}=93.75$ and $46.88 \mathrm{~Hz})$, but increased when a finer spectral resolution $(\Delta \mathrm{f}=23.43 \mathrm{~Hz})$ was used (Figures 4a, 12a, and 13a).

The range of variation in ACI driven solely by changes in the rate of biological sound production by a single species exceeds that reported in most field studies - several of which explain or correlate these changes with trends in biodiversity (Table 1). Although changes in call diversity may also drive changes in ACI (Pieretti et al., 2011; Gasc et al., 2015) these results argue that a causal relationship between the diversity of calls in a marine habitat (i.e., biodiversity) and the complexity of the underwater soundscape should not be assumed.

Our results confirm the sensitivity of ACI to variation in snap and call rate, as suggested by several authors (Table 1), and further elucidate the non-linear nature of this response. Within the low-frequency spectrum, Staaterman et al. (2017) found that ACI dropped during times of chorusing by Bocon toadfish (Amphichthys cryptocentrus), a species that produces tonal boatwhistle calls similar to the oyster toadfish. They noted a drop in ACI coincident with the times of intense calling when the calls overlapped one another and the soundscape
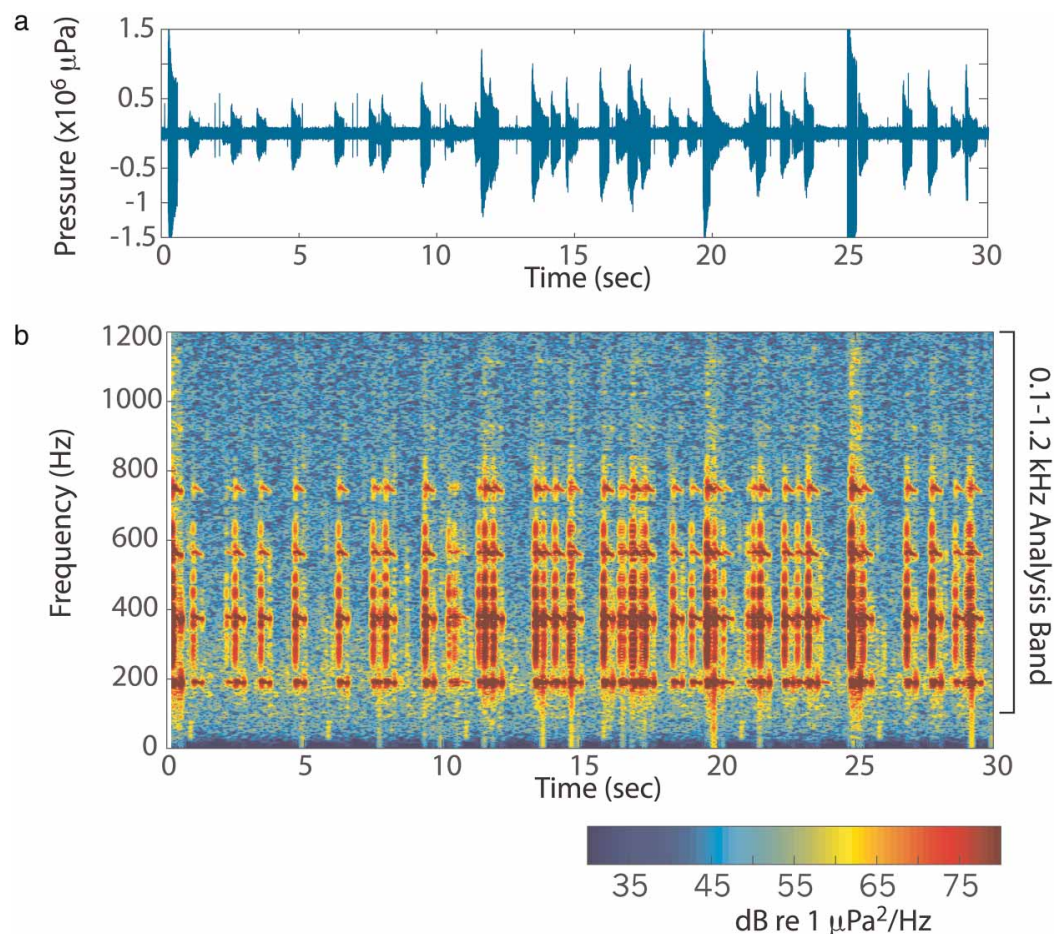

Figure 11. (a) Waveform and (b) spectrogram of a simulated boatwhistle-dominated soundscape.

Amplitudes were drawn randomly from the empirical distribution shown in Figure 10, and call times were assumed to follow a Poisson model with a mean rate of 110 calls/min. Spectrogram displayed using NFFT $=2^{15}$ points $(\Delta f=2.93 \mathrm{~Hz})$ with $95 \%$ overlap. 

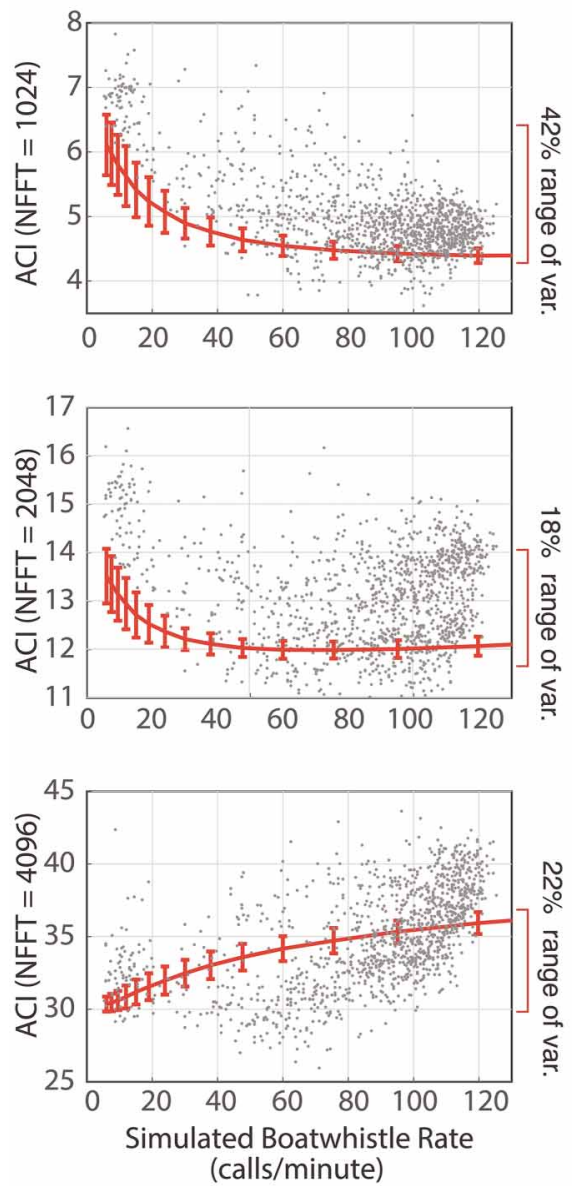

b
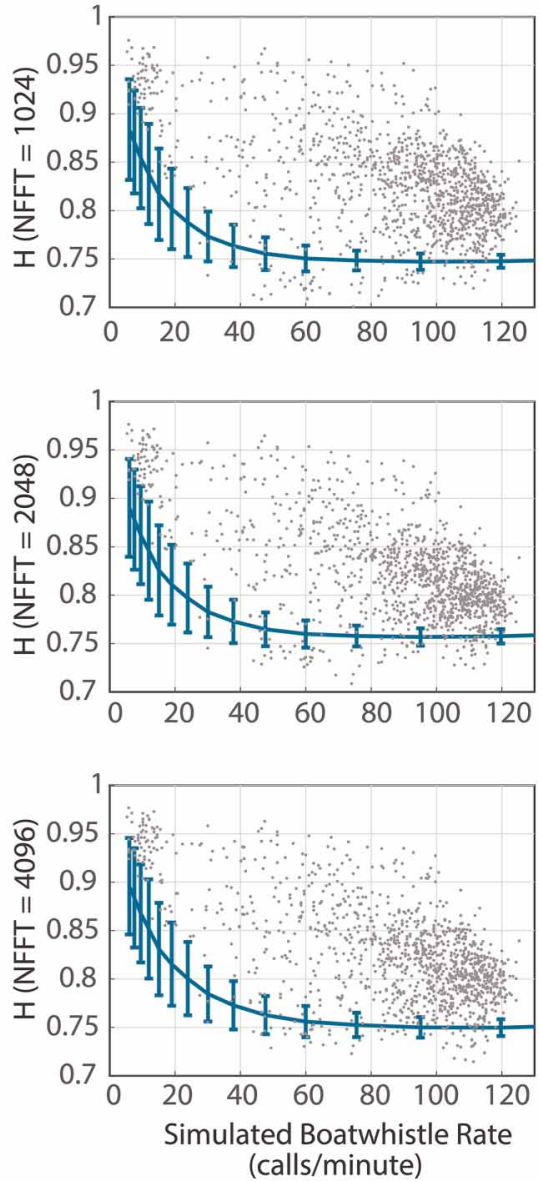

Figure 12. Variation in (a) $\mathrm{ACl}$ and (b) $\mathrm{H}$ with boatwhistle call rate in simulated soundscapes.

Solid line represents the median value based on 1000 synthetic soundscapes generated at each call rate. Vertical error bars denote the standard deviation of these measurements. Grey dots are the field measurements from Figure 4, shown only for reference. Metrics were estimated over the $0.1-1.2 \mathrm{kHz}$ band, calculated using three different NFFT sizes, $1024(\Delta \mathrm{f}=93.75 \mathrm{~Hz}, \Delta \mathrm{T}=0.010 \mathrm{~s}$; top), $2048(\Delta f=46.88 \mathrm{~Hz}, \Delta T=0.021 \mathrm{~s}$; middle), and 4096 ( $\Delta f=23.43 \mathrm{~Hz}, \Delta \mathrm{T}=0.043 \mathrm{~s}$; bottom). Right bracket in (a) denotes range of the $\mathrm{ACl}$ values obtained from the synthetic soundscapes.

became more monotonous. Their analysis was performed using a frequency resolution of $50 \mathrm{~Hz}$, for which a drop in ACI is predicted based on our analysis (Figures $4 \mathrm{a}$ and 12a).

For a soundscape dominated by broadband snaps, trends in ACI were relatively insensitive to time-frequency resolution. However, ACI displayed resolution-dependence when the soundscape was dominated by harmonic boatwhistle sounds (Figure 13a). This trend can be understood by considering the time-frequency resolution used in the analysis relative to the time-frequency characteristics of the signals. To illustrate this, Figure 14a shows spectrograms of a soundscape dominated by snaps displayed with NFFT equal to 1024 (top) and 4096 (bottom). The broadband nature of the signals is evident in either presentation of the data, but when a longer time window $(\mathrm{NFFT}=4096)$ is used, an increasing number of short duration $(<1.5 \mathrm{~ms})$ snaps are incorporated into each time step $(\Delta \mathrm{T}=42.6 \mathrm{~ms})$ in the spectrogram. Figure $14 \mathrm{~b}$ shows the equivalent spectral representations for a boatwhistle-dominated soundscape. Here, both window length choices are short relative to the call duration (350 ms); however, the harmonic character of the soundscape is not evident when the coarser frequency resolution $(\mathrm{NFFT}=1024 ; \Delta \mathrm{f}=94.75 \mathrm{~Hz}$ ) is applied, and the complexity of the spectrogram is visually reduced. ACI may therefore respond differently to call rate variation depending on the time-frequency resolution selected in the analysis and the composition (spectral bandwidth and harmonic spacing) of calls within a recording (13a).

For snap dominated soundscapes, as rates increased from $\sim 100$ to 3500 snaps $/ \mathrm{min}, \mathrm{H}$ values decreased $\sim 0.04$ units in both the field and simulated recordings (Figures 8b, 12b and 13b). As spectral entropy is not sensitive to the number of broadband signals in the recording, this decrease in $\mathrm{H}$ was driven by changes in temporal entropy. Although the magnitude of this drop was small, variations of this order have been reported (Table 2) and correlated with ecological parameters in some field studies (Harris et al., 2016). 

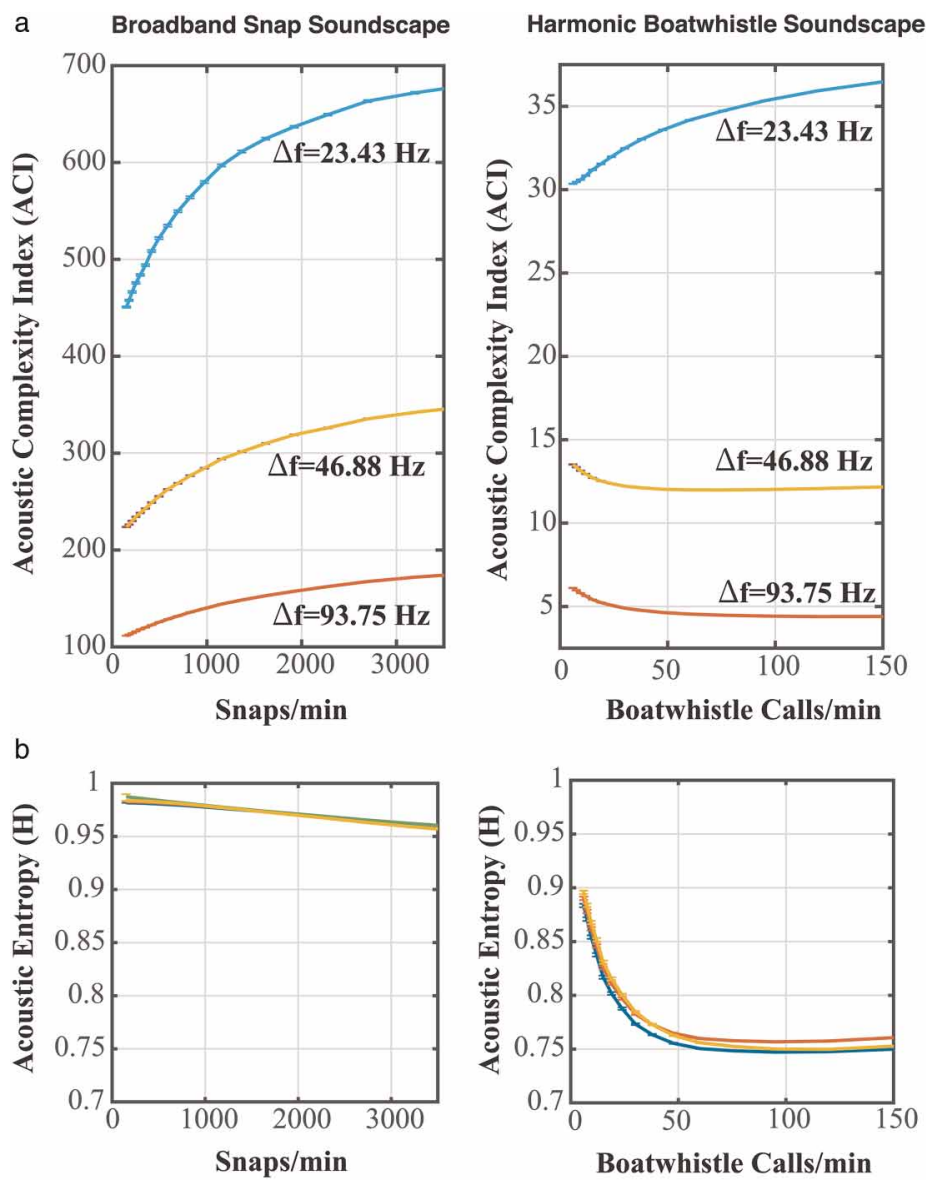

Figure 13. Summary of soundscape synthesis experiments for simulations with either snaps or boatwhistle calls, with the results for analyses conducted using different time-frequency resolutions (Figures 8 and 12) plotted together.

(a) The absolute value of $\mathrm{ACl}$ is strongly dependent on the resolution used in the analysis. For harmonic boatwhistle soundscapes the resolution employed in the analysis also controls whether $\mathrm{ACl}$ increases or decreases in response to greater call rates. (b) The value of $\mathrm{H}$ is largely insensitive to the resolution used in the analysis. $\mathrm{H}$ decreases with increasing rates of sound production, with the magnitude of the response being sensitive to the time and frequency characteristics of the signals (i.e., a larger decrease in $\mathrm{H}$ occurs when longer duration harmonic boatwhistles are simulated at an increasing rate). The frequency resolution of the synthesis experiments is labeled: $\Delta f=93.75 \mathrm{~Hz}(\mathrm{NFFT}=1024, \Delta \mathrm{T}=0.010 \mathrm{~s}) ; \Delta \mathrm{f}=46.88 \mathrm{~Hz}(\mathrm{NFFT}=2048, \Delta T=0.021 \mathrm{~s}) ;$ and $\Delta \mathrm{f}=23.43 \mathrm{~Hz}(\mathrm{NFFT}=4096, \Delta \mathrm{T}=0.043 \mathrm{~s})$.

$\mathrm{H}$ was more sensitive to changes in the rate of harmonic boatwhistle calls than it was to variations in snap rate (Figure 13). Varying the rate of boatwhistle calling between 10 and $120 \mathrm{calls} / \mathrm{min}$ produced a negative $\sim 0.2$ unit change in the total entropy. This decrease was driven by a drop in spectral entropy as energy became increasingly concentrated in the harmonic bands while call rate increased. $\mathrm{H}$, which is calculated from the signal's probability mass functions, did not show the same dependence on spectral resolution observed for ACI. The magnitude of this response suggests that changes in the rate of harmonic calling could explain much of the variability in $\mathrm{H}$ reported in marine field investigations (Table 2). Moreover, these findings are consistent with Staaterman et al.'s (2017) observation of a short-term drop in $\mathrm{H}$ during the most intense periods of calling by the Bocon toadfish.

The simulated soundscape experiments in the present study were, by design, very simple, using a replicated single call, constant variance background noise, and a random (Poisson) call time model parameterized solely by a mean rate. Nonetheless, the ACI and $\mathrm{H}$ derived from snap dominated soundscape simulations closely mirror those calculated for field data from The Bahamas (Figure 8). Boatwhistle calls are inherently more variable than snaps, and the low frequency noise spectrum (e.g., $0.1-1.2 \mathrm{kHz}$ ) in most ocean environments tends to capture a greater diversity of background sources (wind, waves, boats, and other biological sounds) than the higher frequency (e.g., 4-20 kHz) spectrum (Wenz, 1962). Therefore, it is not surprising that field data from Harris Creek show more variability than the simulated soundscapes (Figure 12). Nonetheless, the boatwhistle simulations do reproduce the overall trends observed in the field data, including the resolution-dependent response of $\mathrm{ACI}$ to an increased rate of harmonic calling.

Our results suggest that the amount of variation in ACI and $\mathrm{H}$ reported in the marine literature can be explained largely by variations in the rate of calling by a single sound producer. This does not rule out the 
a
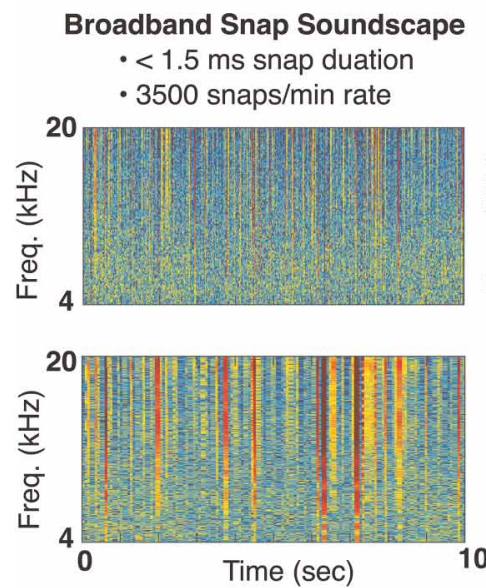

b

Harmonic Boatwhistle Soundscape

- 350 ms call duration

- 120 calls/min rate

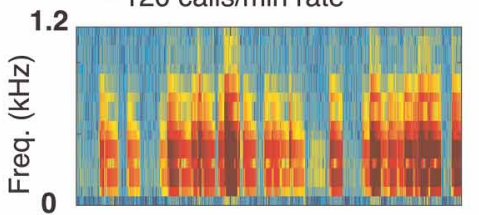

NFFT $=1024$

$\Delta \mathrm{f}=94.75 \mathrm{~Hz}$

$\Delta \mathrm{T}=10.7 \mathrm{~ms}$

Figure 14. Spectrograms of simulated (a) snap- and (b) boatwhistle-dominated soundscapes calculated for NFFT values of 1024 (top row) and 4096 (bottom row).

This highlights how the visual complexity of the spectrogram, and by extension the estimated $\mathrm{ACl}$, can be influence by the resolution used in the analysis. Using larger NFFT sizes will increase spectral resolution, which better represents harmonics within the spectrogram; however, as the NFFT length increases relative to the call duration there is an increased likelihood that multiple calls will be captured within a temporal window. As such, the $\mathrm{ACl}$ will be sensitive to the time-frequency characteristics of calls within a recording, as well as the time-frequency resolution selected for the analysis.

possibility that increasing call diversity can also drive changes in $\mathrm{H}$ and $\mathrm{ACI}$ in some environments; however, it is unclear how the response of these metrics to an increase in call diversity could be readily distinguished (i.e., without counting and classifying calls) from the rate dependence identified here. Nonetheless, the sensitivity of $\mathrm{ACI}$ and $\mathrm{H}$ to a wider range of marine call types and soundscape compositions (e.g., Bolgan et al., 2018) may be the target of future synthesis experiments.

\section{Implications for and future directions in marine ecoacoustics}

Our field and computer-based simulation experiments show that (1) the widely used ecoacoustic metrics ACI and $\mathrm{H}$ respond to changes in the rate of calling of a single species, and (2) that these changes are sensitive to the call composition and the resolution employed in the analysis. These dependencies present a challenge for interpreting variations in ACI and $\mathrm{H}$ when applied to acoustically complex field recordings. While biodiversity and habitat characteristics may display correlations with ACI and H (Tables 1 and 2), a causal relationship between these metrics and the diversity of biological sounds, or the diversity of soniferous species, should not be assumed.

$\mathrm{ACI}$ and $\mathrm{H}$ are the most widely used metrics in marine soundscape studies; however, there are dozens of terrestrial soundscape metrics that might be considered in the marine realm (Sueur et al., 2014; McPherson et al., 2016), including some emerging assessment tools that may better represent the time and/or frequency dynamics within a recording (e.g., Eldridge et al., 2016; Lossent et al., 2017). Soundscape synthesis experiments similar to those conducted in this study (and by Gasc et al., 2015 in terrestrial settings) can provide a tool for understanding these metrics. An assessment of a metric's limitations is necessary before its connection to more traditional ecological indicators (structural habitat complexity, relatively abundance or diversity of species) can be meaningfully investigated.

For rapid ecoacoustic assessment, more traditional acoustic measurements continue to have utility in marine soundscape studies (e.g., Freeman and Freeman, 2016; Ricci et al., 2016; Blondel and Hatta, 2017). Unlike ACI and $\mathrm{H}$, traditionally used sound pressure levels (SPLs) respond linearly to an increased rate of sound production. For example, high-frequency SPLs have been correlated with snap rate in several studies (Bohnenstiehl et al., 2016; Ricci et al., 2016; Lyon, 2018) and used to estimate snapping shrimp abundance and density (Butler et al., 2017). Similarly, low-frequency SPL has been used to estimate fish abundance during peak spawning periods (e.g., Rowell et al., 2017). SPL, however, like many acoustic metrics, may be sensitive to variation in natural (e.g., Matsumoto et al., 2014) or anthropogenic (e.g., Kaplan and Mooney, 2015) background noise.

A more direct accounting of the bioacoustic signals comprising a soundscape would arguably expand the ecological utility of marine passive acoustic datasets. Call detection and classification have long been embraced by 
the marine mammal community (Mellinger and Clark, 2000; Mellinger and Clark, 2006; Kandia and Stylianou, 2006; Jarvis et al., 2008; Roch et al., 2011; Klink and Mellinger, 2011), and recent efforts have shown that similar approaches can be applied to identify the sounds produced by invertebrates (Bohnenstiehl et al. 2016) and fish (Urazghildiiev and Van Parijs, 2016; Ricci et al., 2017). These methods are data-rich in that they provide quantitative information on the timing, source and character (amplitude, duration, frequency) of transient biological sounds - as opposed to metrics, such as ACI and $\mathrm{H}$, which reflect the statistical properties of an entire recording. As advances in statistical (e.g., Noda et al., 2016; Ibrahim et al., 2018) and deep learning make it possible to concurrently track the noises produced by much broader suite of marine animals, call cataloging efforts may eventually supersede the need for proxy metrics that do not directly species-specific contributions to the soundscape.

\section{Acknowledgements}

Thanks to L. Kellog (Virginia Institute for Marine Sciences) and C. Layman (North Carolina State University) for their assistance with hydrophone deployments in Harris Creek MD and The Bahamas, respectively. Portions of this work were initiated as part of a graduate-level special topics course and benefited from discussion with and input from students K. Simmons, E. Voigt, and J. Rudolph. We thank three anonymous reviewers for their constructive comments on this manuscript.

\section{Funding sources}

Funding for this project was provided by a grant from the National Science Foundation (OCE-1234688) to D. Eggleston and D. Bohnenstiehl. Additional support was provided by North Carolina State University's Center for Marine Sciences \& Technology. O. Carretti was supported by a National Science Foundation Graduate Research Fellowship.

\section{Competing interests}

D.R. Bohnenstiehl declares that he has no conflict of interest. R.P. Lyon declares that he has no conflict of interest. O.N. Caretti declares that she has no conflict of interest. S.W. Ricci declares that she has no conflict of interest. D.B. Eggleston declares that he has no conflict of interest.

\section{References}

Au W. W. L. and Banks K. (1998). The acoustics of the snapping shrimp Synalpheus parneomeris in Kaneohe Bay. Journal of the Acoustical Society of America. 103: 41-47. https://doi.org/10.1121/1.423234

Bertucci F., Parmentier E., Lecellier G., Hawkins A. D., and Lecchini D. (2016). Acoustic indices provide information on the status of coral reefs: an example from Moorea Island in the South Pacific. Scientific Reports. 6: 1-9. https://doi.org/10.1038/srep33326

Blondel P. and Hatta A. A. Z. (2017). Acoustic soundscapes and biodiversity - Comparing metrics, seasons and depth with data from the NEPTUNE Ocean Observatory offshore British Columbia. 4th Underwater Acoustics Conference and Exhibition. 763-768.

Bohnenstiehl D. R., Lillis A., and Eggleston D. E. (2016). The curious acoustic behavior of estuarine snapping shrimp: temporal patterns of snapping shrimp sound in sub-tidal oyster reef habitat. PLoS ONE. 11: e0143691. https://doi.org/10.1371/journal.pone.0143691

Bolgan M., O’Brien J., Chorazyczewska E., Winfield I. J., McCullough P., and Gammel M. (2017). The soundscape of Arctic Charr spawning grounds in lotic and lentic environments: can passive acoustic monitoring be used to detect spawning activities? Bioacoustics. 27: 57-85. https://doi.org/10.1080/09524622.2017.1286262

Bolgan M., Amorim M. C. P., Fonseca J., Di Iorio L., and Parmentier E. (2018). Acoustic Complexity of vocal fish communities: a field and controlled validation. Scientific Reports. 8: 10559. https://doi.org/10.1038/s41598-018-28771-6

Buscaino G., Ceraulo M., Pieretti N., Corrias V., Farina A., et al. (2016). Temporal patterns in the soundscape of the shallow waters of a Mediterranean marine protected area. Scientific Reports. 6: 1-13. https://doi.org/10.1038/srep34230

Butler J., Stanley J. A., and Butler M. J. (2016). Underwater soundscapes in near-shore tropical habitats and the effects of environmental degradation and habitat restoration. Journal of Experimental Marine Biology and Ecology. 479: 89-96. https://doi.org/10.1016/j. jembe.2016.03.006

Butler J., Butler M. J. I. V., and Gaff H. (2017). Snap, crackle and pop: Acoustic-based model estimation of snapping shrimp populations in healthy and degraded hard-bottom habitats. Ecological Indicators. 77: 377-385. https://doi.org/10.1016/j.ecolind.2017.02.041

Denes S. L., Miksis-Olds J. L., Mellinger D. K., and Nystuen J. A. (2014). Assessing the cross platform performance of marine mammal indicators between two collocated acoustic recorders. Ecological Informatics. 21: 74-80. https://doi.org/10.1016/j.ecoinf.2013.10.005

Depraetere M., Pavoine S., Jiguet F., Gasc A., Duvail S., and Sueur J. (2012). Monitoring animal diversity using acoustic indices: Implementation in a temperate woodland. Ecological Indicators. 13: 46-54. https://doi.org/10.1016/j.ecolind.2011.05.006

Desjonquères C., Rybak F., Depraetere M., Gasc A., Le Viol I., et al. (2015). First description of underwater acoustic diversity in three temperate ponds. PeerJ. 3: e1393-16. https://doi.org/10.7717/peerj.1393

Eldridge A., Casey M., Moscoso P., and Peck M. (2016). A new method for ecoacoustics? Toward the extraction and evaluation of ecologically meaningful soundscape components using sparse coding methods. PeerJ. 4: e2108. https:/doi.org/10.7717/peerj/ 2108

Farina A. (2014). Soundscape Ecology: Principles, Patterns, Methods and Applications. Springer, New York, New York. pp. 315. 
Farina A. and Gage S. H., editors. (2017). Ecoacoustics: The Ecological Role of Sounds. Wiley, Hoboken, New Jersey. pp. 352.

Farina A. and Morri D. (2008). Source-sink and eco-field: hypothesis and experimental evidences. Proceedings of the X National Congress of the SIEP-IALE. Ecology and Landscape Governance: Experiences and Perspectives. Bari. pp. 365-372.

Farina A., Pieretti N., and Piccioli L. (2011). The soundscape methodology for long-term bird monitoring: A Mediterranean Europe casestudy. Ecological Informatics. 6: 354-363. https://doi.org/10.1016/j.ecoinf.2011.07.004

Fine M. L. (1978). Seasonal and geographic variation of the mating call of the oyster toadfish Opsanus tau L. Oecologia. 36: $45-57$. https://doi.org/10.1007/BF00344570

Freeman L. A. and Freeman S. E. (2016). Rapidly obtained ecosystem indicators from coral reef soundscapes. Marine Ecological Progress Series. 561: 69-82. https://doi.org/10.3354/meps11938

Freeman S. E., Rohwer F. L., D'Spain G. L., Friedlander A. M., Gregg A. K., et al. (2014). The origins of ambient biological sound from coral reef ecosystems in the Line Islands archipelago. Journal of the Acoustical Society of America. 135: 1775-1788. https://doi. org $/ 10.1121 / 1.4865922$

Fuller S., Axel A. C., Tucker D., and Gage S. H. (2015). Connecting soundscape to landscape: Which acoustic index best describes landscape configuration? Ecological Indicators. 58: 207-215. https://doi.org/10.1016/j.ecolind.2015.05.057

Gasc A., Sueur J., Jiguet F., Devictor V., Grandcolas P., et al. (2013). Assessing biodiversity with sound: Do acoustic diversity indices reflect phylogenetic and functional diversities of bird communities? Ecological Indicators. 25: 279-287. https://doi.org/10.1016/j. ecolind.2012.10.009

Gasc A., Pavoine S., Lellouch L., Grandcolas P., and Sueur J. (2015). Acoustic indices for biodiversity assessments: Analyses of bias based on simulated bird assemblages and recommendations for field surveys. Biological Conservation. 191: 306-312. https://doi.org/10.1016/ j.biocon.2015.06.018

Harris S. A., Shears N. T., and Radford C. A. (2016). Ecoacoustic indices as proxies for biodiversity on temperate reefs. Methods in Ecology and Evolution. 7: 713-724. https://doi.org/10.1111/2041-210X.12527

Ibrahim A. K., Chérubin L. M., Zhuang H., Schärer Umpierre M. T., Dalgleish F., et al. (2018). An approach for automatic classification of grouper vocalizations with passive acoustic monitoring. Journal of the Acoustical Society of America. 143: 666-676. https://doi.org/ $10.1121 / 1.5022281$

Jarvis S. M., DiMarzio N. A., Morrissey R. P., and Moretti D. J. (2008). A novel multi-class support vector machine classifier for automated classification of beaked whales and other small odontocetes. Canadian Acoustics. 36: 34-40.

Jung S.-K., Choi B. K., Kim B.-C., Kim B.-N., Park Y., and Lee Y.-K. (2012). Seawater temperature and wind speed dependences and diurnal variation of ambient noise at the snapping shrimp colony in shallow water of Southern Sea of Korea. Japanese Journal of Applied Physics. 51: 07GG09. https://doi.org/10.1143/JJAP.51.07GG09

Kandia V. and Stylianou Y. (2006). Detection of sperm whale clicks based on the Teager-Kaiser energy operator. Applied Acoustics. 67: 1144-1163. https://doi.org/10.1016/j.apacoust.2006.05.007

Kaplan M. B. and Mooney T. A. (2015). Ambient noise and temporal patterns of boat activity in the US Virgin Islands National Park. Marine Pollution Bulletin. 98: 221-228. https://doi.org/10.1016/j.marpolbul.2015.06.047

Kaplan M. B., Mooney T. A., Partan J., and Solow A. R. (2015). Coral reef species assemblages are associated with ambient soundscapes. Marine Ecology Progress Series. 533: 93-107. https://doi.org/10.3354/meps11382

Kaplan M. B., Lammers M. O., Zang E., and Mooney T. A. (2017). Acoustic and biological trends on coral reefs off Maui, Hawaii. Coral Reefs. 37: 121-133. https://doi.org/10.1007/s00338-017-1638-x

Klink H. and Mellinger D. K. (2011). The energy ratio mapping algorithm: A tool to improve the energy-based detection of odontocete echolocation clicks. Journal of the Acoustical Society of America. 129: 1807-1812. https://doi.org/10.1121/1.3531924

Krause B. L. (1993). The Niche Hypothesis. Soundscape Newsletter. 6: 6-10.

Ladich F. (2018). Acoustic communication in fishes: Temperature plays a role. Fish and Fisheries. 19: 598-612. https://doi.org/10.1111/ faf. 12277

Lammers M. O., Brainard R. E., Au W. W. L., Mooney T. A., and Wong K. B. (2008). An ecological acoustic recorder (EAR) for longterm monitoring of biological and anthropogenic sounds on coral reefs and other marine habitats. Journal of the Acoustical Society of America. 123: 1720-1728. https://doi.org/10.1121/1.2836780

Lillis A., Eggleston D. B., and Bohnenstiehl D. R. (2014). Estuarine soundscapes: Distinct acoustic characteristics of oyster reefs compared to soft bottom habitats. Marine Ecology Progress Series. 505: 1-17. https://doi.org/10.3354/meps10805

Lillis A., Perelman J. N., Panyi A., and Mooney A. T. (2017). Sound production patterns of big-clawed snapping shrimp (Alpheus spp.) are influenced by time-of-day and social context. Journal of the Acoustical Society of America. 142: 3311-3320. https://doi.org/10. $1121 / 1.5012751$

Lossent J., Di Iorio L., Valentini-Poirier C. A., Boissery P., and Gervaise C. (2017). Mapping the diversity of spectral shapes discriminates between adjacent benthic biophonies. Marine Ecology Progress Series. 585: 31-45. https://doi.org/10.3354/meps 12370

Luczkovich J. J., Pullinger R. C., Johnson S. E., and Sprague M. W. (2008). Identifying Scieaenid critical spawning habitats by the use of passive acoustics. Transactions of the American Fisheries Society. 137: 576-605. https://doi.org/10.1577/T05-290.1

Lyon R. P. (2018). Fish Biodiversity, Habitat Complexity, and Soundscape Characteristics of Patch Reefs in a Tropical, Back-Reef Nursery, MS Thesis, North Carolina State University, Raleigh, North Carolina.

Matsumoto H., Bohnenstiehl D. R., Tournadre J., Dziak R. P., Haxel J. H., et al. (2014). Antarctic icebergs: A significant natural ocean sound source in the Southern Hemisphere. Geochemistry Geophysics and Geosystems. 15: 3448-3458. https://doi.org/10.1002/ 2014GC005454

McPherson C., Martin B., MacDonnell J., and Whitt C. (2016). Examining the value of the Acoustic Variability Index in the characterization of Australian marine soundscapes. Proceedings of Acoustics 2016: The Second Australasian Acoustics Societies Conference. November 9-11, 2016. Brisbane, Australia.

McWilliam J. N. and Hawkins A. D. (2013). A comparison of inshore marine soundscapes. Journal of Experimental Marine Biology and Ecology. 446: 166-176. https://doi.org/10.1016/j.jembe.2013.05.012

Medeiros C. I., Both C., Grant T., and Hartz S. M. (2017). Invasion of the acoustic niche: variable responses by native species to invasive American bullfrog calls. Biological Invasions. 19: 675-690. https://doi.org/10.1007/s10530-016-1327-7 
Mellinger D. K. and Clark C. W. (2000). Recognizing transient low-frequency whale sounds by spectrogram correlation. Journal of the Acoustical Society of America. 107: 3518-3529. https://doi.org/10.1121/1.429434

Mellinger D. K. and Clark C. W. (2006). MobySound: A reference archive for studying automatic recognition of marine mammal sounds. Applied Acoustics. 67: 1226-1242. https://doi.org/10.1016/j.apacoust.2006.06.002

Montie E. W., Vega S., and Powell M. (2015). Seasonal and spatial patterns of fish sound production in the May River, South Carolina. Transactions of American Fisheries Society. 144: 705-716. https://doi.org/10.1080/00028487.2015.1037014

Noda J., Travieso C., and Sánchez-Rodríguez D. (2016). Automatic taxonomic classification of fish based on their acoustic signals. Applied Sciences. 6: 443. https://doi.org/10.3390/app6120443

Parks S. E., Miksis-Olds J. L., and Denes S. L. (2014). Assessing marine ecosystem acoustic diversity across ocean basins. Ecological Informatics. 21: 81-88. https://doi.org/10.1016/j.ecoinf.2013.11.003

Paynter K. T., Michaelis A., and Lane H. (2012). Oyster population and habitat assessment Harris Creek and the Little Choptank River: 2011 progress report. Submitted to the NOAA Chesapeake Bay Office. College Park, MD: University of Maryland. pp. 1-81.

Picciulin M., Fiorin R., and Bolgan M. (2016). The soundscape of a mussel farm: Biophony and man-made noise levels. Fourth International Conference on the Effects of Noise on Aquatic Life, Dublin, Ireland 10-16 July 2016.

Pieretti N., Farina A., and Morri D. (2011). A new methodology to infer the singing activity of an avian community: The Acoustic Complexity Index (ACI). Ecological Indicators. 11: 868-873. https://doi.org/10.1016/j.ecolind.2010.11.005

Pieretti N., Martire Lo M., Farina A., and Danovaro R. (2017). Marine soundscape as an additional biodiversity monitoring tool: A case study from the Adriatic Sea (Mediterranean Sea). Ecological Indicators. 83: 13-20. https://doi.org/10.1016/j.ecolind.2017.07.011

Ricci S. W., Eggleston D. B., Bohnenstiehl D. R., and Lillis A. (2016). Temporal soundscape patterns and processes in an estuarine reserve. Marine Ecology Progress Series. 550: 25-38. https://doi.org/10.3354/meps11724

Ricci S. W., Bohnenstiehl D. R., Eggleston D. B., Kellogg M. L., and Lyon R. P. (2017). Oyster toadfish (Opsanus tau) boatwhistle call detection and patterns within a large-scale oyster restoration site. PLoS ONE. 12: e0182757. https://doi.org/10.1371/journal.pone. 0182757

Rice A. N., Soldevilla M. S., and Quinlan J. A. (2017). Nocturnal patterns in fish chorusing off the coasts of Georgia and eastern Florida. Bulletin of Marine Science. 93: 455-474. https://doi.org/10.5343/bms.2016.1043

Roch M. A., Klinck H., Baumann-Pickering S., Mellinger D. K., Qui S., et al. (2011). Classification of echolocation clicks from odontocetes in the Southern California Bight. Journal of the Acoustical Society of America. 129: 467-475. https://doi.org/10.1121/1. 3514383

Rountree R. A., Gilmore R. G., Goudey C. A., Hawkins A. D., Luczkovich J., and Mann D. (2006). Listening to Fish: Applications of passive acoustics to fisheries science. Fisheries. 31: 433-446.

Rowell T. J., Demer D. A., Aburto-Oropeza O., Cota-Nieto J. J., Hyde J. R., and Erisman B. E. (2017). Estimating fish abundance at spawning aggregations from courtship sound levels. Nature Scientific Reports. 7: 1-14. https://doi.org/10.1038/s41598-017-03383-8

Staaterman E., Paris C. B., DeFerrari H. A., Mann D. A., Rice A. N., and D’Alessandro E. K. (2014). Celestial patterns in marine soundscapes. Marine Ecology Progress Series. 508: 17-32. https://doi.org/10.3354/meps10911

Staaterman E., Ogburn M. B., Altieri A. H., Brandl S. J., Whippo R., et al. (2017). Bioacoustic measurements complement visual biodiversity surveys: Preliminary evidence from four shallow marine habitats. Marine Ecology Progress Series. 575: 207-215. https://doi. org/10.3354/meps 12188

Sueur J., Pavoine S., Hamerlynck O., and Duvail S. (2008a). Rapid acoustic survey for biodiversity appraisal. PLoS ONE. 3: e4065. https://doi.org/10.1371/journal.pone.0004065

Sueur J., Aubin T., and Simonis C. (2008b). Equipment review: Seewave, a free modular tool for sound analysis and synthesis. Bioacoustics. 18: 213-226.

Sueur J., Farina A., Gasc A., Pieretti N., and Pavoine S. (2014). Acoustic indices for biodiversity assessment and landscape investigation. Acta Acustica United with Acustica. 100: 772-781. https://doi.org/10.3813/AAA.918757

Tavolga W. N. (1958). Underwater sounds produced by two species of toadfish, Opsanus tau and Opsanus beta. Bulletin of Marine Science of the Gulf and Caribbean. 8: 309-284.

Tricas T. C. and Boyle K. S. (2014). Acoustic behaviors in Hawaiian coral reef fish communities. Marine Ecology Progress Series. 511: 1-16. https://doi.org/10.3354/meps 10930

Urazghildiiev I. R. and Van Parijs S. M. (2016). Automatic grunt detector and recognizer for Atlantic cod (Gadus morhua). The Journal of the Acoustical Society of America. 139: 2532-2540. https://doi.org/10.1121/1.4948569

Wall C. C., Simard P., Lembke C., and Mann D. A. (2013). Large-scale passive acoustic monitoring of fish sound production on the West Florida Shelf. Marine Ecology Progress Series. 484: 173-188. https://doi.org/10.3354/meps10268

Watanabe M., Sekine M., Hamada E., Ukita M., and Imai T. (2002). Monitoring of shallow sea environment by using snapping shrimps. Water Science and Technology. 46: 419-424. https://doi.org/10.2166/wst.2002.0772

Wenz G. (1962). Acoustic Ambient Noise in the Ocean: Spectra and Sources. Journal of the Acoustical Society of America. 34: 1936-1956. https://doi.org/10.1121/1/1909155

Willis T. J. (2001). Visual census methods underestimate density and diversity of cryptic reef fishes. Journal of Fish Biology. 59: 1408-1411. https://doi.org/10.1111/j.1095-8649.2001.tb00202.x 